Universidad de Lima

Escuela de Posgrado

Maestría en Derecho Empresarial

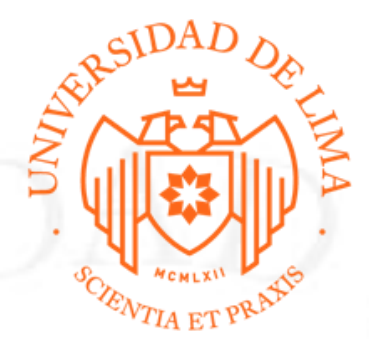

\title{
LA NECESIDAD DE UN MARCO LEGAL \\ PARA EL CROWDFUNDING EN EL MERCADO PERUANO
}

Trabajo de investigación para optar el

Grado Académico de Maestro en Derecho Empresarial

\author{
Mary Laura Rodríguez Garzón \\ Código 20163795 \\ Lessenia Joanna Vásquez Morales
}

Código 20163796

Asesor

Jorge Miranda Benavides

Lima - Perú 
Julio de 2019 


\section{LA NECESIDAD DE UN MARCO LEGAL PARA EL CROWDFUNDING EN EL MERCADO PERUANO}

\section{THE NEED FOR A LEGAL FRAMEWORK FOR CROWDFUNDING IN THE PERUVIAN MARKET}




\section{TABLA DE CONTENIDO}

INTRODUCCIÓN..................................................

CAPÍTULO I: ASPECTOS GENERALES DEL CROWDFUNDING ......3

1.1. Antecedentes del crowdfunding ..................................... 3

1.2. Factores del crowdfunding ....................................

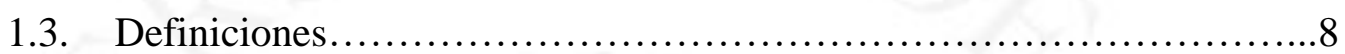

1.4. Características............................................... 9

1.5. Primeras prácticas del crowdfunding .............................. 10

1.6. Ventajas e Inconvenientes del crowdfunding.........................11

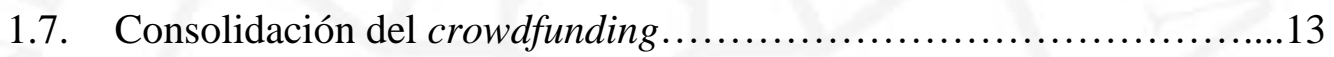

CAPÍTULO II: PLANTEAMIENTO DEL PROBLEMA...................14

2.1. Modalidades de crowdfunding .................................. 15

2.1.1. Donación o Donation based crowdfunding ..........................16

2.1.2. Recompensa o Reward based crowdfunding ..........................16

2.1.3. Lending o debt based crowdfunding ................................17

2.1.4. Equity based crowdfunding o crowdinvesting....................... 19

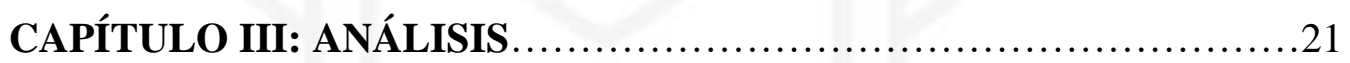

3.1. Regulación para las fintech .....................................21

3.1.1. Tipos de Propuestas Regulatorias para las fintech....................21

3.1.2. Propuestas Legislativas Peruanas..................................22

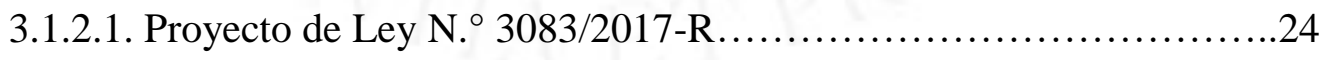

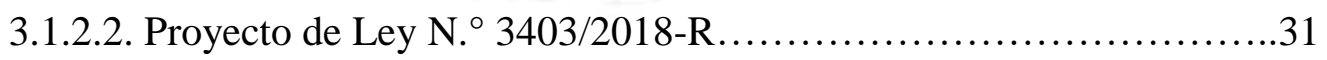

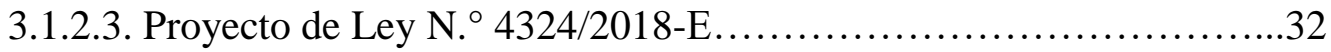

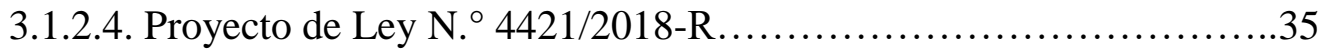

3.2. Desregulación.................................................... 35

3.2.1. Autorregulación.................................................... 36

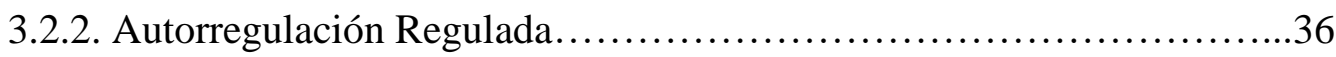

3.3. Propuestas de Autorregulación para el Perú............................38 
3.3.1. Gobierno Corporativo y Buen Gobierno Corporativo....................38

3.3.2. Principios Generales............................................40

3.3.3. Propuesta de Código de Conducta para Plataformas....................43

3.3.4. Sandbox Regulatorio..........................................44

3.3.5. Regtech ..................................................47

CONCLUSIONES.................................................48

RECOMENDACIONES ............................................... 49

REFERENCIAS ......................................................... 


\section{RESUMEN}

El presente trabajo de investigación tiene como finalidad dar a conocer la importancia de contar con una regulación para que sea positiva la actuación del crowdfunding en nuestro país. En la investigación se determina que en nuestro país se debe desarrollar un marco legislativo idóneo y no restrictivo para el crowdfunding. Para ello, proponemos que los actores tanto del sector público como privado se asocien y planteen de modelos innovativos de autorregulación.

Palabras claves: crowdfunding, fintech, autorregulación, plataformas de financiamiento participativo, principios. 


\begin{abstract}
The purpose of this investigation is to raise awareness of the importance of having a regulation so that the performance of crowdfunding in our country be positive. In the investigation it is determined that in our country an appropriate and non-restrictive legislative framework for crowdfunding should be developed. To this end, we propose that actors from both the public and private sectors associate and propose innovative models of self-regulation.
\end{abstract}

Keywords: crowdfunding, fintech, self-regulation, participatory financing platforms, principles. 


\section{INTRODUCCIÓN}

El presente trabajo de investigación tiene como finalidad explicar el fenómeno del crowdfunding y argumentar la necesidad de su regulación en nuestro país.

En tal sentido, desarrollamos esta investigación dividiéndola en tres capítulos. En el primer capítulo describimos el fenómeno de crowdfunding, indicando sus antecedentes, factores, características; asimismo, señalamos las iniciativas legislativas que conformarían el marco legal del crowdfunding en nuestro país. En el segundo capítulo nos planteamos las siguientes interrogantes ¿se debe o no regular el crowdfunding en el Perú?, ¿qué tipo de regulación se requiere? Del mismo modo, desarrollamos las cuatro modalidades del crowdfunding citando algunos ejemplos. Y finalmente, en el tercer capítulo, señalamos los tipos de propuestas regulatorias que algunos autores proponen para las Fintech; explicamos también la autorregulación como alternativa de producción legislativa de los privados, indicamos las similitudes que existen entre el Proyecto de Ley N. ${ }^{\circ} 3083 / 2017-C R$ y la Ley de Fomento Española, que regula el régimen jurídico de las plataformas de financiamiento colectivo, y comentamos los otros tres (03) Proyectos de Ley que se encuentran en estudio en el Congreso de la República. Por otro lado, señalamos los principios de: la Ley de Fomento Española, Ley Fintech de México, Proyecto de Ley N. ${ }^{\circ}$ 3083/2017 - CR, Principios de la Alianza del Pacífico, Código de Buenas Prácticas para las Fintech y las Insurtech de España, entre otros.

Por lo expuesto, a manera de una conclusión anticipada, creemos que resulta necesario regular el crowdfunding desde la perspectiva de la autorregulación regulada y el Buen Gobierno Corporativo, para ello recogemos y fijamos diversos principios, tomados de documentos nacionales e internacionales, que servirían de directrices para la creación de un Código de Conducta que permitirá a las empresas que administren las plataformas de Crowdfunding crear Manuales de Procedimientos para su desarrollo.

Asimismo, consideramos que este trabajo de investigación podría contribuir para futuras investigaciones, y servir como motivación para que las empresas encargadas de administrar estas plataformas de financiamiento colectivo tomen la iniciativa a cooperar con el Estado mediante la autorregulación y consolidarse como empresas responsables y profesionales comprometidas con la inclusión financiera. 


\section{CAPÍTULO I: ASPECTOS GENERALES DEL CROWDFUNDING}

\subsection{Antecedentes del crowdfunding:}

El término crowdfunding proviene de dos vocablos anglosajones "crowd", que significa multitud, y “funding” que significa financiación (EAE Business School, 2015, párr. 6).

Para Rodríguez de las Heras (2013), el crowdfunding es conocido como "financiación en masa o colectiva", y consiste en un fenómeno que tiene como base la tecnología, mediante la cual las personas dan a conocer sus iniciativas de negocio y buscan un financiamiento colectivo (p. 102).

Para referirnos a los antecedentes del crowdfunding, tomamos como referencia el artículo de Elena Gil Moreno (2015), "Nuevos activismos sociales en la era digital: de las masas al crowd", y sus fuentes.

Iniciamos esta explicación mencionando una de las fuentes citadas por Gil Moreno, Le Bon (1895) con su obra "Psicología de las masas", donde desarrolla el concepto de masa y sus características:

La masa es siempre intelectualmente inferior al individuo aislado pero que, desde el punto de vista de los sentimientos y de las acciones que estos sentimientos provocan, la masa puede, dependiendo de las circunstancias, ser mejor o peor que el individuo. Todo depende de la sugestión a la cual la masa se halla expuesta (p. 18). Entre las características especiales de las masas hay varias - tales como impulsividad, irritabilidad, incapacidad de razonar, la ausencia de juicio y de espíritu crítico (p. 19).

Para Le Bon, las masas se caracterizaban por ser irracionales; sin embargo, con el pasar de los años y el desarrollo de la tecnología, tal como lo menciona Gil Moreno, observamos que este concepto fue cambiando, por lo que resultó necesario realizar un replanteamiento del concepto de masa. 
Un concepto actual de masa, lo señala Rheingold (2004), otra fuente de Gil Moreno, en su obra "Multitudes inteligentes: La próxima revolución social”:

El nuevo conocimiento y las nuevas tecnologías han posibilitado y evolución del tamaño máximo del grupo social operativo, desde la tribu hasta los países y las coaliciones globales. El conocimiento y las tecnologías que desencadenaron el salto del clan a la tribu, al país, al mercado y a la red tienen una característica en común: amplificaron el modo en que piensan y se comunican los individuos, expandiendo así la capacidad de compartir lo que sabían (p.48).

Por lo expuesto, nos permitimos citar a dos fuentes de Gil Moreno:

- "Agencia compartida significa que las tecnologías no son instrumentos pasivos, sino que contribuyen a generar dinámicas, que nos hacen hacer ciertas cosas y que nosotros las hacemos hacer otras (...) Esos usos los descubren y los inventan los usuarios" (Lasén, 2009, párr.19).

- "Ni Internet ni ninguna otra tecnología, para el caso, puede ser origen de una causalidad social (...) Asumir que los movimientos han sido creados por la internet implicaría caer en lo que algunos denominan el determinismo tecnológico" (Castells, 2012, p.274).

Nosotras compartimos opinión con lo antes expuesto, pues la tecnología es el medio que permite a los individuos compartir ideas y encontrar un apoyo colaborativo para lograr sus objetivos, lo que denominan el nuevo activismo social.

Reforzamos nuestra opinión, citando nuevamente a Rheingold (2004):

¿Qué aportan las comunidades virtuales para que el individuo comparta constantemente información con personas a las que no ha visto nunca cara a cara? La respuesta de Smith fue: «capital de red social, capital de conocimiento y comunión»; es decir, el individuo deposita parte de sus conocimientos y estados de ánimo en la red, y a cambio obtiene mayores cantidades de conocimiento y oportunidades de sociabilidad (pp. 2-3).

Por lo expuesto, concordamos con lo señalado por Sagol (2017) citando a Rheingold, al referirse que nos encontramos viviendo una era tecnológica, donde "las 
nuevas prácticas sociales basadas en la cooperación propiciados por las nuevas tecnologías y el acceso permanente a Internet móvil inalámbrico en la mano” (Sagol, 2017, párr. 3).

En la actualidad, diversos emprendedores tienen proyectos que buscan financiamiento en el sistema tradicional, pero que muchas veces lamentablemente no logran concretarse. En ese sentido, la experiencia internacional ha demostrado que a través de la tecnología y la cooperación en comunidad se puede desarrollar una vía alterna al financiamiento tradicional.

A nivel mundial, el fenómeno de crowdfunding viene desarrollando importantes proyectos y nuestro país no es ajeno a ese fenómeno, pues como otros países, esta práctica se acentúa en mayor porcentaje cada día.

Hay información periodística que señala que este fenómeno llegó al Perú en el año 2013, a través de plataformas que podían apoyar con capital semilla para el emprendimiento (La Voz de los Emprendedores, 2018, párr. 1).

Es así que, en el año 2014, medios de comunicación señalan que la plataforma Kapitalzocial lanzó entre la comunidad diversas convocatorias, captando alrededor de 10 proyectos donde se practicaban las modalidades de crowdfunding como Donación y Pre ventas cobrando comisiones del 5\% de lo conseguido (Yun, 2014, párr. 14, 18).

Ante tal situación, diversas fueron las opiniones que proponían regular este fenómeno. Entre los fundamentos de esta corriente se encuentra el incentivo de acceso al capital, pues permitirá "que los empresarios puedan tener acceso a todo tipo de capital rápidamente y dentro de un mercado competitivo y eficiente" (Estudio Echecopar, 2017, párr. 10).

Es así que se acentúa el término Fintech, al que nos referiremos más adelante, pero que es necesario entender su significado. Fintech, proviene de la fusión de dos los vocablos en inglés finance y technology, "es una industria en la que las empresas usan la tecnología para brindar servicios financieros de manera eficiente, ágil, cómoda y confiable" (Fintech México, 2018, párr. 1). 
Por el año 2017 en nuestro país, se desarrolló el Primer Lima Fintech Fórum, iniciativa de la Universidad del Pacífico, en el cual se congregaron diversos actores nacionales e internacionales, públicos y privados, donde cada uno de ellos compartió sus experiencias.

Para tener una idea de cómo este fenómeno ha ido aumentado en el mercado peruano, tomamos como referencia la información que comparte Finnovista Perú, conformado por "profesionales del mundo tecnológico, capital riesgo, instituciones financieras y emprendedores", quienes elaboran Reportes Fintech, que para el caso de nuestro país es denominado Fintech Radar Perú, en el cual se puede apreciar que el crowdfunding ocupa el 9\% del mundo fintech (Finnovista, 2017, párr. 5).

En el mencionado Fórum se dieron a conocer las diversas iniciativas estatales y civiles que se vienen desarrollando en torno al mundo fintech y por ende del crowdfunding. Así, la Superintendencia de Banca, Seguros y AFP (SBS) indicó que vienen desarrollando una propuesta legislativa para regular la fintech sin limitar su desarrollo; asimismo, la Asociación de Emprendedores indicó que sigue de cerca estas iniciativas estatales, donde participa activamente proporcionando sus aportes (Silva, 2017, p.46).

Sin embargo, la Superintendencia de Mercado de Valores (SMV), como ente regulador, emitió una alerta informativa mediante la cual advirtió a los inversionistas “que la financiación por suscripción denominada crowdfunding a través de plataformas de internet que emplean la modalidad de emisión de valores o aportes de capital, no está autorizada" (Superintendencia de Mercado de Valores, 2018, párr. 2).

En tal sentido, la Superintendencia de Mercado de Valores - SMV señaló que todo "acto de colocación o venta de valores mobiliarios es una oferta pública de valores, por lo que debe estar bajo supervisión de la SMV” (Diario Gestión, 2014, párr. 2).

En mayo del 2018, se desarrolló por segunda vez el Lima Fintech Fórum, donde un representante del Banco Central de Reserva del Perú - BCR indicó la necesidad de crear un marco regulatorio que "proteja al cliente y a la Fintech así como al sistema financiero" (Diario Gestión, 2018, párr. 2). 
En tal sentido, actualmente se han presentado al Congreso de la República las siguientes iniciativas legislativas: Proyecto de Ley N. ${ }^{\circ}$ 3083-2017-CR, presentado el 27 de junio de 2018, mediante el cual proponen una Ley que regule el régimen jurídico de las Plataformas de Financiamiento Participativo. Así también, el 18 de setiembre de 2018 se presentó el Proyecto de Ley N. ${ }^{\circ}$ 3403-2018-CR que declara de interés nacional y necesidad pública la regulación de la tecnología financiera (Fintech), el 13 de mayo de 2019 se presentó el Proyecto de Ley N. ${ }^{\circ}$ 4324/208-PE mediante el cual propone la regulación del financiamiento participativo financiero para administrar las plataformas y el 05 de junio de 2019 se presentó el Proyecto de Ley N. ${ }^{\circ}$ 4421/2018-CR por el cual se norma el desarrollo de la tecnología financiera en el Perú. Es necesario señalar que las tres primeras iniciativas legislativas se encuentran pendiente de debate ante el Pleno del Congreso de la República, pues cuentan con un Dictamen Favorable Sustitutorio de la Comisión de Economía, Banca, Finanzas e Inteligencia Financiera.

\subsection{Factores del Crowdfunding:}

De acuerdo con la investigación realizada, existen diversos factores que influyeron en el nacimiento del crowdfunding. Para Rodríguez (2013), existen tres factores que convergen en el fenómeno del crowdfunding:

- Factor económico: Por un lado, la dependencia en el sistema financiero tradicional para obtener créditos y por otro, la crisis económica que a diversos países les tocó asumir.

- Factor social: El crowdfunding es considerado una participación social, donde los emprendedores recurren a la convocación de esfuerzos, con la finalidad de lograr una colaboración colectiva para la ejecución de sus diversos proyectos.

- Factor tecnológico: El desarrollo tecnológico, — las redes y el internet—, ha hecho posible la interacción de la comunidad para diversos fines (pp. 104-105).

\subsection{Definiciones:}


En esta sección, realizaremos un enunciado de los principales conceptos de fintech y crowdfunding, a fin de identificar y analizar, más adelante, las principales características de este último.

Considerando el contexto peruano, es preciso primero explicar el significado de "fintech". Fintech proviene de las palabras en inglés "Financial Technology" y representa la provisión de servicios y productos financieros a través del empleo de la innovación y desarrollos tecnológicos (Superintendencia de Mercado de Valores, 2017, p. 3).

A través del Fintech, los emisores, los inversionistas y los intermediarios del mundo se comunican, investigan, socializan, comparten, cooperan, recaudan recursos, compiten y comercian de maneras que son muy diferentes del pasado, desafiando así el paradigma que ha regido la regulación hasta el día de hoy (Franco, 2017, p. 5).

Para la Superintendencia de Banca, Seguros y AFP (SBS), son "modelos de negocio que ofrecen productos y servicios financieros haciendo uso intensivo de la tecnología". Se indica también que se dan "mediante distintos tipos de iniciativas como el financiamiento participativo o crowdfunding, entre otros" (Superintendencia de Banca, Seguros y AFP - Memoria Anual, 2017, p. 23).

De acuerdo con Asociación de Bancos del Perú (Asbanc), "las fintech pueden ser definidas como empresas o startup que haciendo uso de la tecnología, proveen soluciones financieras digitales para necesidades específicas de la población”. Es así que en la actualidad muchas entidades financieras llevan a cabo sus actividades con estas empresas por el impacto en las finanzas (Asociación de Bancos del Perú - 2017, p. 1).

Por lo expuesto, podemos resumir que la definición de Financial Technology, de acuerdo con Carney, quien es citado por Bregante en su obra El reto de la regulación Fintech en el Sistema Peruano, "es la innovación tecnológica orientada al desarrollo de nuevos modelos de negocio que generan un efecto material en el mercado financiero" (Bregante, 2017, p. 2). 
Por otro lado, para Rodríguez (2013) el crowdfunding “consiste en la creación de un entorno electrónico para la agrupación de un colectivo, la aportación de ideas, recursos y fondos y la interacción en red dirigidas a apoyar conjuntamente proyectos” (p. 107).

Para Alemany y Bultó (2014) el crowdfunding "consiste en una convocatoria abierta, fundamentalmente a través de internet, para solicitar recursos financieros, ya sea en forma de donación o a cambio de algún tipo de recompensa y/o derechos de voto con el fin de apoyar proyectos" (p. 7).

Según Burkett (2011), crowdfunding "is a process where entrepreneurs, artists, and nonprofits raise money for their projects, businesses, or organizations by gaining the support of many people on the internet who collectively contribute money to projects to which they feel some affinity" (p. 66).

Para la Asociación Española de Crowdfunding, es un "sistema de cooperación que permite a cualquier persona creadora de proyectos, reunir una suma de dinero entre muchas personas para apoyar una iniciativa empresarial" (Coronado y Larrañaga, 2015, p. 206).

\subsection{Características:}

La principal característica del crowdfunding es la base comunitaria y en masa, la cual permite agrupar esfuerzos, recursos e ideas. Como señala García y Alonso (2014), "la Comisión Europea en su comunicación habla que el término surgió para designar habitualmente convocatorias hechas al público con vistas a recaudar fondos para un determinado proyecto" (p. 235).

Una segunda característica es el empleo de tecnología. El crowdfunding engloba el uso de una plataforma tecnológica online, que usa como medio para la presentación de proyectos de inversión ideas e iniciativas sociales, entre otras, con el fin de obtener recompensas o rendimientos financieros, lo que nos lleva a la tercera característica, que viene a ser un canal de financiación, el cual puede usarse de formas distintas, como el micromecenazgo, o financiación a cambio de recompensas, o entrega de productos 
elaborados con los fondos recaudados, o adaptar fórmulas de inversión para obtener una remuneración financiera.

\subsection{Primeras prácticas del Crowdfunding:}

Nos referiremos en esta sección a la práctica de la industria cinematográfica, pues fue en este ambiente cultural que se produjeron los primeros casos de crowdfunding.

En el caso del cine, para los guionistas que inician su carrera, el llevar a cabo sus ideas es toda una odisea, pues para ellos no solo es necesario contar con una interesante historia, sino obtener el financiamiento. En esta sección nos referiremos aquellas ideas culturales que se realizaron gracias al financiamiento colectivo de la sociedad.

Riot Cinema Collective elaboró el guión del film "El Cosmonauta", primer film que gracias al crowdfunding llegó a pantallas españolas. Estuvo basado en la modalidad de recompensa, pues la persona que aportaba como mínimo 2 euros, podía aparecer entre los créditos de la película y recibir merchandising. De esta experiencia se puede concluir que cuanto más detallada sea la idea a compartir en las redes, la credibilidad del público aumentará (Gallego, 2011, pp. 162-163, 165).

Otro proyecto de cine es "Lugar para ayer", una película francesa que logró recaudar una importante cantidad de euros en el 2004 a través del crowdfunding basado también en la modalidad de recompensa, pues los aportantes podían asistir a la fecha de estreno, obtener una copia de la película, entre otros (Coronado y Larrañaga, 2015, p. 210).

\subsection{Ventajas e Inconvenientes del Crowdfunding:}

En esta sección tomaremos como referencia el Resumen de las ventajas e inconvenientes del crowdfunding para las iniciativas empresariales, las masas y los inversores señaladas por Alemany y Bultó (2014), en su obra “Crowdfunding: nueva forma de financiación para los emprendedores":

\begin{tabular}{|l|l|}
\hline VENTAJAS & INCONVENIENTES \\
\hline
\end{tabular}




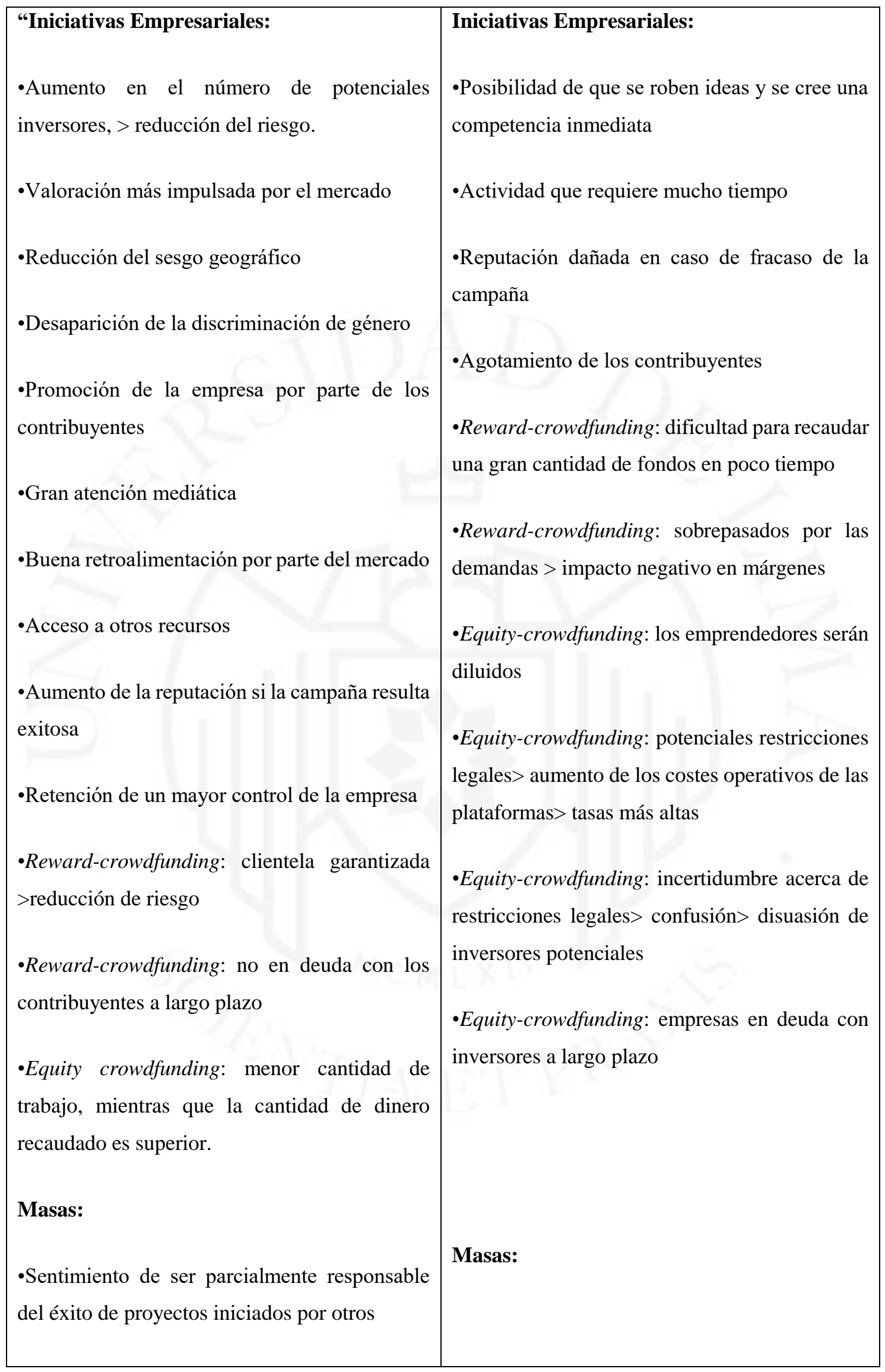




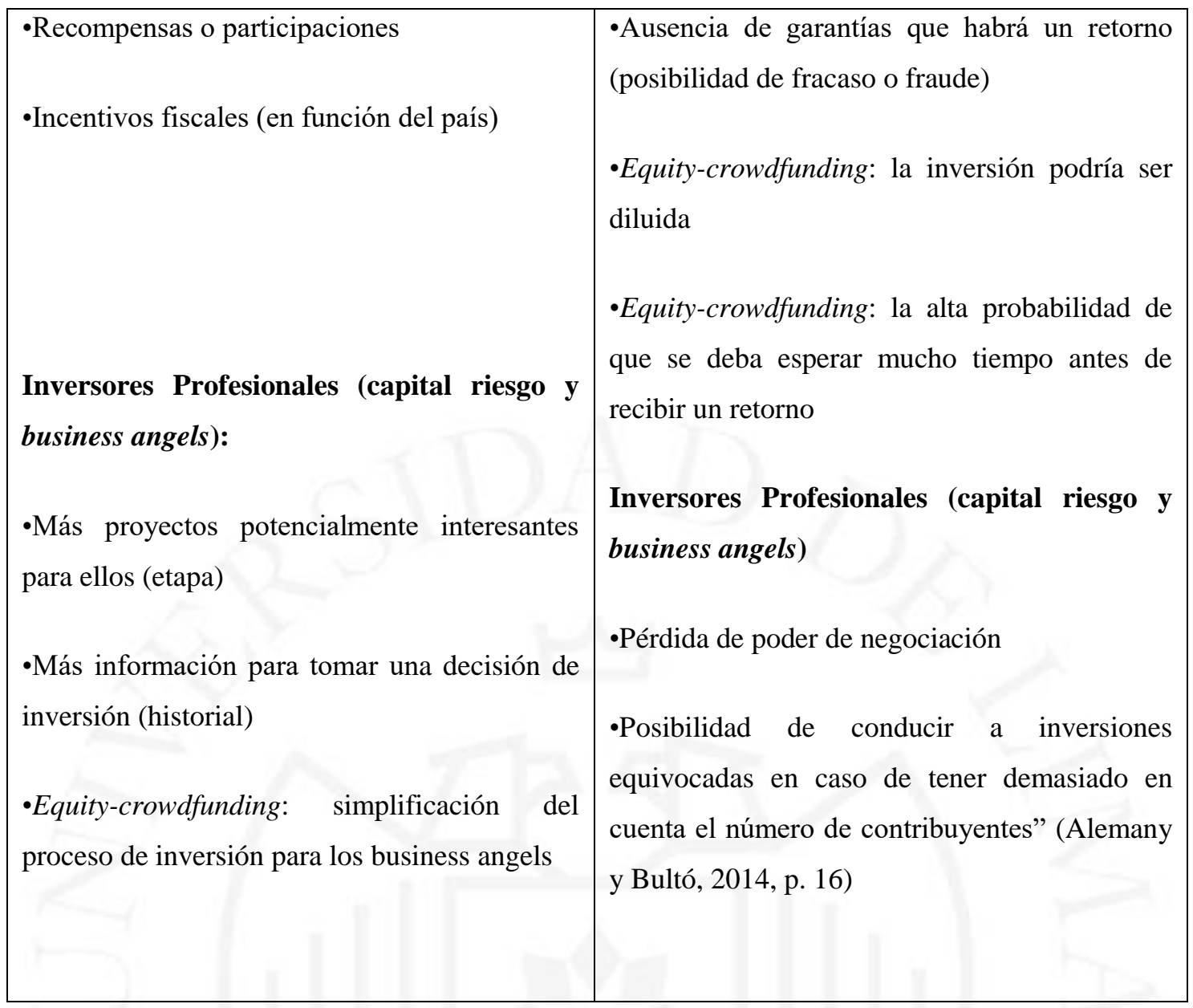

Se puede afirmar que las personas cuyos proyectos y/o ideas buscan obtener un financiamiento para llevarlos a cabo, tienen una reducción de riesgo al utilizar el crowdfunding, debido a que proporciona a un grupo de inversores mayor al que podría acceder un emprendedor utilizando un método convencional de financiamiento. Otro punto a favor es que el valor del proyecto es proporcionado y promovido por el mercado, siendo este el que acerca al público interesado en invertir o formar parte de una idea innovadora.

Si bien es cierto, no todo es positivo, sino que requiere de mucha dedicación por parte del emprendedor y riesgo por parte del inversor. Consideramos que es un método con mayor posibilidad de acceso a un financiamiento sin trámites engorrosos que conlleva utilizar un método tradicional, que muchas veces cierra puertas a proyectos con muchas probabilidades de éxito, pero sin tener la confianza de los Bancos o garantías suficientes para respaldar al emprendedor. 


\subsection{Consolidación del Crowdfunding:}

Por lo expuesto, señalamos que son tres causas las que han permitido la consolidación del crowdfunding:

a) La masificación de las plataformas de intercambio les permite interactuar a muchas personas, conformando una gran comunidad virtual capaz de luchar por una idea de negocio y su financiación.

b) El acceso a Internet y a las redes sociales permite acortar distancias, situación que los emprendedores aprovechan para difundir sus ideas de negocio, así como buscar el apoyo financiero de personas que estén interesadas o identificadas con el proyecto.

c) Lamentablemente, con la crisis financiera, los mecanismos tradicionales de financiamiento cambiaron sus políticas, por lo que recortó el financiamiento a las nuevas iniciativas de negocio promovido por emprendedores. (Alemany y Bultó, 2014, p. 13) 


\section{CAPÍTULO II: PLANTEAMIENTO DEL PROBLEMA}

Para explicar la problemática que surge en torno a la práctica del crowdfunding, iniciamos este este capítulo con el siguiente enunciado:

Cabe destacar que el crowdfunding ha venido dando sus primeros pasos sin contar con una regulación específica. De hecho, en la mayoría de los países, el crowdfunding financiero forma parte de la llamada "banca en la sombra", que al quedar fuera del sistema bancario tradicional está sujeto a una regulación más laxa. No obstante, en la medida que estas actividades han ido ganando tracción, la regulación ha avanzado gradualmente o el sistema ha decidido autorregularse para aumentar la confianza (Diario Gestión, 2015, párr. 4).

Nuestro país aún no cuenta con un marco normativo promulgado ya que como mencionamos, las iniciativas legislativas propuestas aún se encuentran pendientes de debate ante el Congreso de la República; sin embargo, las prácticas de crowdfunding se incrementan cada día. En ese sentido, cabe plantearse las siguientes interrogantes ¿se debe o no regular el crowdfunding en el Perú?, ¿qué tipo de regulación se requiere?

Países como Estados Unidos y España fueron los pioneros en la creación de marcos legales para desarrollar el crowdfunding en sus diversas modalidades, otorgando seguridad jurídica a los participantes. En Estados Unidos, el 05 de abril de 2012 se reglamentó el crowdfunding con Ley JOBS Act (Jumpstart Our Business Startups), y en España, el 27 de abril de 2015 se promulgó la Ley N. ${ }^{\circ}$ 5/2015, de fomento de la financiación empresarial, mediante la cual regula la figura del crowdfunding como una nueva modalidad de inversión a través de medios electrónicos, otorgando la seguridad jurídica al inversor mediante la fiscalización por parte de la Comisión Nacional del Mercado de Valores (CNMV).

Posteriormente, países como Argentina y México decidieron también regular el crowdfunding. Así, en Argentina, el 12 de abril de 2017 se promulgó la Ley de Apoyo al Capital Emprendedor N. ${ }^{\circ} 27.349$ y con fecha 29 de diciembre de 2017 mediante Resolución General 717-E/2017 se reglamentó los Sistemas de Financiamiento Colectivo. Este marco legal permite, tal como lo indica el artículo $22^{\circ}$ de la mencionada 
Ley, la implementación del sistema de financiamiento colectivo para fomentar la industria del capital emprendedor en el mercado de capitales. Asimismo, señala que será la Comisión Nacional de Valores la entidad encargada de fiscalizar las únicas formas de participación, tal y como lo señala el artículo 24 de la mencionada Ley. Asimismo, en México, el 09 de marzo de 2018 se promulgó la Ley para Regular las Instituciones de Tecnología Financiera (Ley Fintech), que tiene como propósito incentivar la innovación en los productos y servicios financieros impulsados por nuevas tecnologías. Regula las plataformas denominadas Instituciones de Tecnología Financiera (ITF), así también, los llamados Modelos Novedosos conocidos por otras legislaciones como los "Regulatory Sandbox", que permiten la creación de proyectos y empresas innovadoras por empresas dentro de un marco seguro, con límites y restricciones claramente definidos.

En el caso de México, nos llamó la atención que antes de que se promulgara la Ley para Regular las Instituciones de Tecnología Financiera, las principales plataformas se asociaron y fundaron la Asociación de Plataformas de Fondeo Colectivo (Afico). Asimismo, crearon un Código de Ética con el "principal objetivo de promover el modelo y defender sus intereses, estableciendo códigos de prácticas que sean adoptados por todas las plataformas y profesionales del crowdfunding en el país” (Afico, 2016, párr. 1).

En nuestra opinión, la falta de regulación en nuestro país puede ser considerada como una "banca paralela", tal como lo señala Zunzunegui (2015) "shadow banking o banca paralela", que puede conllevar a riesgos muy significativos para el sistema jurídico de cada país por "constituir una amenaza a la estabilidad bancaria y una fuente de fraude" (p. 145).

La experiencia internacional nos permite profundizar en las herramientas para hacer frente al problema que puede ocasionar la falta regulación del crowdfunding en nuestro país.

\subsection{Modalidades de Crowdfunding:}

Para profundizar el análisis del crowdfunding es necesario señalar que tiene diversas modalidades de operación. Para explicar cada una de ellas, citaremos a Rodríguez de las Heras (2013), quien nos señala cuatro (04) formas de encaminar una financiación colectiva 


\subsubsection{Donación o Donation based crowdfunding:}

Esta modalidad de crowdfunding se caracteriza por "no ofrece un retorno a las personas o empresas que aportan los fondos” (Nuevo Financiero, 2017, párr.5).

Una vez que los promotores publican sus proyectos a través de las plataformas informáticas buscando financiamiento, las personas interesadas realizan sus aportaciones mediante contribuciones voluntarias sin ánimo de obtener algo a cambio.

Los proyectos que se buscan financiar a través de esta modalidad son en su totalidad sin ánimo de lucro o filantrópicos, culturales, humanitarios o sociales (Rodríguez, 2013, p. 1012).

Como ejemplo de esta modalidad señalamos a la plataforma española Teaming, considerada una herramienta tecnológica que permite recaudar fondos para causas sociales a través de donaciones de un (01) euro al mes. El procedimiento que realiza la plataforma es el siguiente: publica el proyecto en una página web totalmente gratuito, recauda los fondos y los transfiere a la cuenta corriente de la causa social sin cobrar comisiones. Los futuros donantes buscan en la plataforma la lista de Grupos Teaming y eligen la ayuda social que desean apoyar, se suscriben e indican la forma de pago (Teaming, 2018, párr. 1).

\subsubsection{Recompensa o Reward based crowdfunding:}

En este tipo de crowdfunding los interesados en financiar un determinado proyecto realizan aportaciones a la espera de algo a cambio (puede ser un bien o servicio), la misma que no puede ser de índole financiero. Para Alemany y Bultó (2014) esta recompensa "corresponde al producto o servicio que el promotor está planeado ofrecer en el futuro" (p. 8).

Para Rodríguez de las Heras (2013) existen dos (02) modalidades de Recompensa según "la relación entre la cuantía de la aportación y el valor relativo de recompensa":

a) El llamado "recompensa de valor simbólico". Por ejemplo, en el caso de contribuir a la realización de un concierto de una banda de musical, la recompensa que espera el fan aportante es el que le entreguen una entrada al concierto o un 
CD. En este caso, el aporte ve recompensado su contribución con la entrada o CD que reciba, por lo que, esta recompensa tendrá asignado un "valor simbólico" superior al importe entregado.

b) El llamado "el precio del producto o servicio que el aportante abona por anticipado". Por ejemplo, en el caso de contribuir a la creación de un video juego, el aportante lo que realiza es el pago por adelantado por el bien, pues su contribución permitirá el desarrollo del video juego y la recompensa otorgada es recibir un ejemplar del video juego. La atracción aquí es la rebaja del precio del bien (pp. 1012 - 1013).

Un ejemplo de esta modalidad de crowdfunding la representó la campaña de crowdfunding lanzada en la plataforma Kickstarter en el año 2012, con el reloj inteligente denominado "Pebble". Lo llamativo de esta campaña es que llegó a la meta de financiamiento en tan solo 8 horas. La recompensa que motivó a sus aportantes fue recibir como recompensa relojes con la inscripción "Kickstarter Edition" y ser las primeras personas en tener este reloj. La clave del éxito estuvo en la "creación de recompensas exclusivas, limitadas y valiosas para los mecenas" (La Tribu Colaborativa, 2015, párr. 2, $4,7)$.

\subsubsection{Lending o debt based crowdfunding:}

Esta modalidad se basa en "operaciones de préstamo entre el colectivo de usuarios (prestamistas) y los promotores del proyecto que buscan financiación” (Rodríguez, 2013, p. 1013).

De acuerdo con García y Alonso (2014):

La microfinanciación colectiva basada en préstamos se soporta en préstamos obtenidos de los aportantes donde los demandantes actúan como prestatarios y los aportantes de créditos como prestamistas. Los préstamos conllevan riesgos por las dificultades de verificar la solvencia de las entidades que actúan como prestatarios (p. 236).

Respecto a este tipo de crowdfunding, Rodríguez (2013) señala dos formatos de presentación: 
- Gestor de la Plataforma que actúe como intermediario: Es decir, que "recauda las aportaciones de los prestamistas — captando fondos reembolsables del públicoy garantizando así la devolución de los préstamos en determinadas condiciones" (p. 1013).

De configurarse de este formato, surgirían "consecuencias regulatorias", pues estas son prácticas exclusivas de las entidades financieras sujetas a regulación y supervisión por el ente regulador.

- Plataforma para la interacción directa entre prestamistas y prestatarios: "La función del intermediario (match-maker) es simplemente proporcionar a los usuarios el acceso y el uso de este entorno electrónico para el intercambio de información" (p. 1013).

Con esta modalidad se limita la intervención regulatoria y de supervisión.

Un ejemplo de esta modalidad es la plataforma Arboribus, empresa supervisada por la CNMV de España que proporciona a sus clientes "soluciones financieras ágiles y eficientes" (Arboribus, 2018, párr. 1 y 2).

Un proyecto financiado por medio de esta plataforma fue Oxbridge, un centro de enseñanza del idioma inglés que tuvo gran acogida por su metodología, que decidió expandir sus servicios a nivel de empresas vía teleconferencia, y para ello recurrió al financiamiento alternativo mediante Arboribus. (Arboribus, 2018, párr. 1 y 4).

Arboribus permite invertir decidiendo la cantidad a invertir, obteniendo cuotas fijas por la inversión.

\subsubsection{Equity based crowdfunding o crowdinvesting:}

Consiste en la financiación en masa de proyectos mediante la participación en el capital de la sociedad promotora. Así, la contribución recibida se trata como aportación de capital y el aportante se convierte en socio o accionista de la sociedad promotora del proyecto, con el derecho a participar, en las condiciones legales y estatutarias, en los beneficios de la compañía o recibir, de otro modo, parte de las ganancias del proyecto (Rodríguez, 2013, p. 1014). 
Como bien indica Franco (2017), este modelo esta "limitado para ciertos inversionistas calificados que puedan asumir el riesgo derivado de la operación"; asimismo, "puede presentarse una oferta pública de valores, y por tanto, el emisor estaría sujeto a cargas regulatorias" (p. 11).

Esta modalidad destaca algunos riesgos en su aplicación. Según Franco (2017), presenta siete (07); sin embargo, consideramos señalar dos (02) que se ajustan a principalmente a modalidad de acciones:

- $\quad$ Riesgo de llevar a cabo actividades que requieren autorización estatal.

- Riesgo de divulgación. Puede ser que los datos que se ofrezcan a los inversionistas no sean transparentes (p.18).

Un ejemplo de esta modalidad de crowdfunding es Hemav, startup dedicada a ofrecer soluciones con vehículos aéreos no tripulados (drones). Para lograr su objetivo, Hemav buscó la financiación en una modalidad del Crowdfunding. Para ello recurrió a la plataforma Crowdcube, con lo cual Hermav cedía a sus inversores el 20\% de la empresa.

Para que el proyecto sea aceptado por la Plataforma, en primer lugar, debía contar con un plan de negocio y un plan de financiación, y presentar su propuesta de retorno de inversión.

El principal atractivo para los inversores fueron las condiciones de retorno de la inversión, que consistía en distribuir el 5\% de los beneficios después de impuestos en forma de dividendos en 2016 y el 15\% en los años siguientes, además, de una rentabilidad mínima del 30\%, lo que la hacía que la participación sea más atractiva

En Crowdcube, los inversores se dividen en dos grupos, los pequeños inversores que adquieren derechos económicos sobre la empresa a la que se financia, mientras que el gran inversor adquiere, además de los derechos económicos, los derechos políticos. (BBVA - Case Study: Hemav 2015, párr. 6 y 7).

\section{CAPÍTULO III: ANÁLISIS}


Iniciamos este capítulo afirmando que para que sea positiva la actuación del crowdfunding en nuestro país es necesario regularlo en todas sus modalidades, con ello, se podría evitar conductas fraudulentas, delimitar el campo de la intermediación financiera, garantizar la seguridad jurídica, proteger el interés público y crear empresas sostenibles. En ese sentido, somos de la opinión que nuestras autoridades deberán desarrollar un marco legal flexible, que no limite la iniciativa emprendedora y fomente en las empresas que administren estas plataformas, la cooperación activa con el Estado.

\subsection{Regulación para las Fintech:}

Considerando que el crowdfunding forma parte del mundo fintech, consultamos la obra de Bregante (2017) titulada "Regulación 2.0: El Reto de la Regulación Fintech en el Sistema Financiero Peruano", donde señala el papel de la regulación dentro de la promoción de la innovación tecnológica, describiéndola como un elemento que puede facilitar el desarrollo tecnológico, pero que también puede restringirlo (p. 4).

Asimismo, señala que el objetivo principal de la regulación en el ámbito financiero "es proteger los intereses del público, cautelando la estabilidad, la solvencia y la transparencia del sistema financiero". De la misma manera indica que "se trata de encontrar un punto de equilibrio que permita otorgar flexibilidad a las fintech para que a su vez sigan innovando y ayudando a la inclusión financiera, pero sin comprometer los interés del público" (Bregante, 2017, p. 5).

Se observa que en el ámbito financiero el desarrollo tecnológico no solo trae consigo aspectos positivos (innovación tecnológica e inclusión financiera), sino también puede generar riesgos para el sistema (lavado de activos) y para los consumidores (fraudes); por ello, el Estado deberá implementar una regulación efectiva para el crowdfunding, y de esa forma proteger el interés público y regular la actividad.

\subsubsection{Tipos de Propuestas Regulatorias para las Fintech:}

Para Bregante (2017) las propuestas regulatorias para las fintech pueden clasificarse en tres (03) tipos:

a) Activa: Propuesta regulatoria que se caracteriza por "establecer una regulación específica a partir de una estrecha colaboración con las empresas fintech". En este 
caso el ente regulador promueve las fintech, preserva la solidez y estabilidad del mercado, busca la colaboración de las empresas fintech para contar con una regulación específica (Bregante, 2017, p. 5).

b) Pasiva: Propuesta regulatoria que se caracteriza por el rol neutral del ente regulador, "no fomenta ni restringe las fintech, sino que éstas se adaptan a la regulación vigente" (Bregante, 2017, p. 6).

c) Restrictiva: Propuesta regulatoria donde "el regulador se encuentra más preocupado por preservar la solidez y estabilidad del mercado financiero antes que en colaborar con las fintech" (Bregante, 2017, p. 6).

Según Bregante (2017), nuestro país necesita una regulación activa para las fintech, caracterizada por la estrecha relación entre el regulador y las empresas fintech. Dicha situación se estaría presentando en la actualidad; prueba de ello es el compromiso de los diferentes actores que están procurando estrechar lazos, participando en Foros Fintech, y colaborando con el Estado vertiendo opinión técnica de las iniciativas legislativas.

\subsubsection{Propuestas Legislativas Peruanas:}

Nuestro país asumió el compromiso de la inclusión financiera, instaurando la Comisión Multisectorial de Inclusión Financiera liderada por el Ministerio de Economía y Finanzas (MEF), la cual el 21 de julio de 2015 presentó la Estrategia Nacional de Inclusión Financiera (SBS, 2014, párr. 2-3).

En dicha Estrategia Nacional de Inclusión Financiera se plantean diversos objetivos, entre ellos, el Objetivo N ${ }^{\circ} 3$ denominado Financiamiento, el cual señala como acción prioritaria "el diseño de políticas que permitan minimizar las asimetrías de información entre las fuentes de financiamiento y las empresas que lo requieran”, todo en el marco de las Mipyme. Asimismo, señala "la promoción del desarrollo de mercados de capitales y otras herramientas alternativas de financiamiento como el crowdfunding" (Estrategia Nacional, 2015, pp. 44-45).

Por otro lado, tenemos el Acuerdo Nacional suscrito el 22 de julio de 2002, diseñado con "el fin de definir un rumbo para el desarrollo sostenible del país y afirmar su gobernabilidad democrática" (Acuerdo Nacional, 2014, párr. 1-2). 
Dicho Acuerdo Nacional cuenta con 35 Políticas, pero en este caso, solo nombraremos a la Política 18 denominada Búsqueda de la competitividad, productividad y formalización de la actividad económica.

Por lo expuesto, somos de la opinión de que el Estado Peruano está realizando sus mayores esfuerzos por cumplir con tales compromisos. Así, ante el Congreso de la República se presentaron los siguientes proyectos: el Proyecto de Ley N. ${ }^{\circ} 3083 / 2017-C R$ respecto al régimen jurídico de las Plataformas de Financiamiento Colectivo y el Proyecto de Ley N. ${ }^{\circ} 3403 / 2018-C R$ respecto al interés nacional de regular las Fintech.

$\mathrm{Al}$ respecto, el Poder Ejecutivo de conformidad con lo dispuesto por el artículo $107^{\circ}$ de la Constitución Política presentó ante el Congreso el 13 de mayo de 2019, el Proyecto de Ley N. ${ }^{\circ}$ 4324/2018-PE - Ley que regula el Financiamiento Participativo Financiero.

Por otro lado, la Congresista Marisol Espinoza Cruz, el 05 de junio de 2019 presentó el Proyecto de Ley N. ${ }^{\circ} 4421 / 2018-C R$, Ley que norma el desarrollo de la Tecnología Financiera en el Perú.

En tal sentido, a julio de 2019, presentamos el siguiente cuadro en el que se muestra el panorama de las iniciativas legislativas presentadas ante el Congreso de la República respecto al crowdfunding y el fintech.

\begin{tabular}{|c|c|c|c|c|}
\hline \multicolumn{5}{|c|}{ INICIATIVAS LEGISLATIVAS } \\
\hline & \multicolumn{2}{|c|}{ PROYECTO DE LEY } & $\begin{array}{c}\text { FECHA DE } \\
\text { PRESENTACIÓ } \\
\mathbf{N} \\
\end{array}$ & SEGUIMIENTO \\
\hline $\begin{array}{l}1 \\
\circ\end{array}$ & 3083/2017-CR & $\begin{array}{l}\text { Ley que regula el régimen } \\
\text { jurídico de las plataformas de } \\
\text { financiamiento participativo - } \\
\text { PFP }\end{array}$ & $27 / 06 / 2018$ & \multirow{3}{*}{$\begin{array}{c}\text { Dictamen Favorable de } \\
\text { Comisión de Economía } \\
\text { (3083/2018-CR, } \\
\text { 3403/2018-CR y } \\
\text { 4324/2018-PE) }\end{array}$} \\
\hline 2 & 3403/2018-CR & $\begin{array}{c}\text { Ley que declara de interés } \\
\text { nacional y necesidad pública la } \\
\text { regulación de la tecnología } \\
\text { financiera - Fintech }\end{array}$ & $18 / 09 / 2018$ & \\
\hline $\begin{array}{l}3 \\
0\end{array}$ & 4324/2018-PE & $\begin{array}{l}\text { Ley que regula el financiamiento } \\
\text { participativo financiero }\end{array}$ & $13 / 05 / 2019$ & \\
\hline
\end{tabular}


\begin{tabular}{|c|c|c|c|c|}
4 & $\mathbf{4 4 2 1 / 2 0 1 8 - C R}$ & $\begin{array}{c}\text { Ley que norma el desarrollo de la } \\
\text { tecnología financiera en el Perú - } \\
\text { Fintech }\end{array}$ & $05 / 06 / 2019$ & $\begin{array}{c}\text { En comisión de } \\
\text { Economía }\end{array}$ \\
\hline
\end{tabular}

Es necesario señalar que con fecha 13 de junio de 2019, la Comisión de Economía, Banca Finanzas e Inteligencia Financiera recomienda la aprobación de los tres Proyectos de Ley N. ${ }^{\circ} 3083 / 2017-C R$, N. ${ }^{\circ} 3403 / 2018-$ CR y N. ${ }^{\circ} 4324 / 2018-P E$, con el texto sustitutorio del Proyecto de Ley N. ${ }^{\circ}$ 4324/2018-PE. Sin embargo, a julio de 2019, aún la Comisión de Defensa al Consumidor no emite su dictamen.

Por otro lado, el Proyecto de Ley N. ${ }^{\circ} 4421 / 2018-C R$ aún se encuentra en estudio ante la Comisión de Economía desde el 10 de junio de 2019.

\subsubsection{Proyecto de Ley $N^{\circ}$ 3083/2017-CR:}

El congresista Percy Eloy Alcalá Mateo, por intermedio del Grupo Parlamentario Fuerza Popular, presentó ante el Congreso el 27 de junio de 2018 el Proyecto de Ley N. ${ }^{\circ}$ 3083/2017-CR - "Proyecto de Ley mediante el cual propone la Ley que regula el régimen jurídico de las Plataformas de Financiamiento Participativo - PFP”, la cual desde el 3 de julio de 2018 se encuentra en la Comisión Economía, Banca, Finanzas e Inteligencia Financiera para su debate.

La Exposición de Motivos de este Proyecto de Ley, señala que el objetivo de esta iniciativa legislativa es:

Regular el régimen jurídico de las Plataformas de Financiamiento Participativo y establecer normas a las que deben sujetarse las personas jurídicas que administren estas plataformas, con el fin de financiar el emprendimiento y la innovación. La finalidad exclusiva de las PFP es poner en contacto mediante plataformas de páginas web, redes sociales u otros medios, a una pluralidad de inversionistas con las personas que desean financiar sus proyectos, con el fin de impulsar el emprendimiento (Proyecto de Ley N. ${ }^{\circ 3083 / 2017-C R, ~ 2018, ~ p . ~ 24) . ~}$

Respecto a los beneficios del financiamiento participativo, manifestamos nuestro desacuerdo cuando señalan que la única forma de financiar el crecimiento de los emprendedores en etapas tempranas es consiguiendo socios para su empresa, es decir, 
desarrollando crowdfunding de inversión o equity (Proyecto de Ley N. ${ }^{\circ} 3083 / 2017-C R$, 2018, p. 26).

$\mathrm{Al}$ respecto, indicamos que son cuatro las modalidades de crowdfunding por las cuales se puede lograr un financiamiento para los emprendedores, todo dependerá de la envergadura del proyecto.

Es necesario señalar que este Proyecto de Ley tiene gran similitud con la Ley 5/2015 — "Ley de Fomento de la Financiación Empresarial” —, publicada el 28 de abril de 2015 en España, que en su Título V regula el Régimen Jurídico de las Plataformas de Financiación Participativa.

A continuación, hemos elaborado un cuadro comparativo entre el Proyecto de Ley N. ${ }^{\circ} 3083 / 2017-C R$ y la Norma española con los principales temas que abordan a fin de mostrar similitudes y diferencias.

\begin{tabular}{|c|c|}
\hline $\begin{array}{c}\text { PERÚ } \\
\text { Proyecto de Ley } \text { N. }^{\circ} \text { 3083/2017-CR }\end{array}$ & $\begin{array}{l}\text { ESPA ̃̃A } \\
\text { Ley 5/2015 }\end{array}$ \\
\hline $\begin{array}{l}\text { "Proyecto de Ley que regula el régimen jurídico de las } \\
\text { plataformas de financiamiento participativo - PFP" }\end{array}$ & $\begin{array}{c}\text { "Ley de fomento de la financiación empresarial" } \\
\text { TÍTULO V } \\
\text { "Régimen jurídico de las plataformas de } \\
\text { financiación participativa" }\end{array}$ \\
\hline $\begin{array}{l}\text { Objeto: }\left(\text { art. } 1^{\circ} \text { ) Establece las normas a las que deben }\right. \\
\text { sujetarse las personas jurídicas cuyo objeto social sea } \\
\text { administrar PFP con el fin de financiar el } \\
\text { emprendimiento y la innovación. } \\
\text { Finalidad de las PFP: (art. } 2^{\circ} \text { ) Poner en contacto } \\
\text { mediante plataformas web u otros medios electrónicos, } \\
\text { a una pluralidad de inversionistas, sean personas } \\
\text { naturales o jurídicas, y a personas, que deseen } \\
\text { financiamiento de sus proyectos, las cuales serán } \\
\text { denominados promotores. } \\
\text { Los proyectos podrán ser financiados bajo alguna de las } \\
\text { modalidades señaladas en el art. } 16^{\circ} \text {. }\end{array}$ & \\
\hline $\begin{array}{l}\text { Definiciones: }\left(\text { art. } 4^{\circ}\right) \\
\text { *Financiamiento Participativo o Crowdfunding: Uso de } \\
\text { pequeñas cantidades de recursos de varios individuos } \\
\text { para donar o financiar, usualmente sin colateral, } \\
\text { proyectos, negocios o actividades personales, a través de } \\
\text { una plataforma con conexión a internet. La plataforma } \\
\text { se encarga principalmente de seleccionar y publicar } \\
\text { proyectos. } \\
\text { *Financiamiento Participativo o Crowdfunding } \\
\text { Financiero: Requiere legislación local, comúnmente } \\
\text { utilizada por Mypes y nuevos emprendimientos. } \\
\text { Dos tipos: }\end{array}$ & $\begin{array}{l}\text { Plataformas de financiación participativa (art. } \\
\left.46^{\circ}\right)\end{array}$ \\
\hline
\end{tabular}


-Crowdfunding de inversión o equity: donde a los inversionistas se les dan acciones o capital de la empresa a cambio.

-Crowdfunding de préstamo o Crowdlending: se busca financiación a cambio de pagar un interés al inversionista, como si fuera un banco, pero con muchas personas detrás apoyando el proyecto.

*Plataformas de Financiamiento Participativo (PFP):

Son las empresas que conectan de manera profesional a través de páginas web y medios electrónicos a inversionistas que buscan rendimiento financiero con promotores de proyectos que buscan financiamiento.

\section{PFP no comprendidas en la Ley: (art. $5^{\circ}$ )}

Aquellas actividades ejercidas por personas que utilicen PFP, mediante la cual se busque obtener financiamiento a través de:

- Donación

- Venta de bienes y servicios

- Préstamos o mutuo sin intereses

- Otras modalidades no comprendidas en el art. $16^{\circ}$

Título II
Plataformas de Financiamiento Participativo - PFP

Registro de Plataforma: $\left(\operatorname{art} 7^{\circ}\right)$

-A cargo de la SMV, será público y deberá contener los datos actualizados.

Autorización de Funcionamiento y Requisitos: (art. $8^{\circ}$ )

-SMV autorizará el funcionamiento y las inscribirá en el Registro de PFP a cargo de la SMV.

-Deberá presentar los siguientes documentos: estatuto social, copia literal, Ruc, Póliza de seguros de acuerdo al monto de proyecto, restricciones para ser accionistas, socios u organizadores.
*Plataformas de Financiación Participativa: son empresas autorizadas cuya actividad consiste en poner en contacto, de manera profesional y a través de páginas web $\mathrm{u}$ otros medios electrónicos, a una pluralidad de personas físicas o jurídicas que ofrecen financiación a cambio de un rendimiento dinerario, denominados inversores, con personas físicas o jurídicas que solicitan financiación en nombre propio para destinarlo a un proyecto de financiación participativa, denominados promotores.

\section{No tendrán consideración de PFP, cuando la}

financiación sea captada a través de: (art. $46^{\circ}$ )

- Donaciones.

- Venta de bienes y servicios.

- Préstamos sin intereses.

\section{Registro (art. 54 ${ }^{\circ}$ )}

Las plataformas de financiación participativa serán inscritas en el registro correspondiente de la Comisión Nacional del Mercado de Valores. Este registro será público y deberá contener los datos actualizados.

\section{Requisitos para ejercer la actividad y requisitos} financieros (art. $55^{\circ}$ y $56^{\circ}$ )

Tener objeto social exclusivo de PFP, domicilio social, revestir la forma de sociedad de capital, capital social desembolsado en efectivo, administradores de reconocida honorabilidad, buena organización administrativa y contable, contar con medios adecuados para garantizar la seguridad, confidencialidad, fiabilidad y capacidad, disponer de un reglamento interno de conducta que contemple los posibles conflictos y términos de participación, prever mecanismos para mantener proyectos en caso de cese de actividad.

Solicitud de autorización e inscripción (art. 57) La solicitud de autorización deberá ir acompañada de los siguientes documentos:

a) En caso de nueva creación (proyecto de Estatutos y certificación registral negativa) 


\begin{tabular}{|c|c|}
\hline . & $\begin{array}{l}\text { b) Programa de actividades, servicios, incluidos los } \\
\text { auxiliares, que se pretenden realizar. } \\
\text { c) Descripción de la organización administrativa y } \\
\text { contable. } \\
\text { d) Relación de socios con participación. } \\
\text { e) La relación de administradores y de quienes hayan } \\
\text { de ejercer como directores generales. } \\
\text { f) Reglamento interno de conducta. } \\
\text { g) Una descripción de los procedimientos y medios } \\
\text { para la presentación de quejas y reclamaciones. } \\
\text { h) Declaración de honorabilidad. } \\
\text { Autorización (art. 53 }) \\
\text { 1. La Comisión Nacional del Mercado de Valores } \\
\text { autorizará e inscribirá en su registro correspondiente } \\
\text { a las plataformas de financiación participativa, } \\
\text { previo informe preceptivo y vinculante del Banco de } \\
\text { España } \\
\text { Revocación, suspensión y renuncia de la } \\
\text { autorización (art. } 59^{\circ} \text { ) } \\
\text { 1. La Comisión Nacional del Mercado de Valores } \\
\text { podrá revocar la autorización: } \\
\text { a) Si interrumpen de hecho las actividades } \\
\text { específicas autorizadas durante un período superior } \\
\text { a un año. } \\
\text { b) Cuando se hubiera dictado resolución judicial de } \\
\text { apertura de la fase de liquidación en un } \\
\text { procedimiento concursal. } \\
\text { 3. La autorización podrá ser suspendida: } \\
\text { a) Cuando existan indicios fundados de la comisión } \\
\text { de infracciones previstas y descritas en este título. } \\
\text { b) Cuando existan indicios fundados que permitan } \\
\text { deducir que la influencia ejercida por las personas } \\
\text { que posean una participación significativa pueda } \\
\text { resultar en detrimento de la gestión correcta y } \\
\text { prudente de la plataforma, y hasta que se resuelva la } \\
\text { situación de conflicto de interés. } \\
\text { 4. La renuncia a la autorización deberá ser } \\
\text { comunicada a la Comisión Nacional del Mercado de } \\
\text { Valores }\end{array}$ \\
\hline $\begin{array}{l}\text { Servicios de las PFP: }\left(\text { art. } 9^{\circ}\right) \\
\text { *Principales: } \\
\text {-Recepción, selección y publicación de proyectos. } \\
\text {-Desarrollo, establecimiento y explotación de canales } \\
\text { de comunicación } \\
\text { *Adicionales: } \\
\text {-Asesoramiento a los promotores } \\
\text {-Análisis de los proyectos recibidos, determinación del } \\
\text { nivel de riesgos. } \\
\text {-Habilitación de canales de comunicación a distancia } \\
\text {-Modelos de contratos } \\
\text {-Transmisión de información de los proyectos } \\
\text {-La reclamación judicial y extrajudicial. } \\
\text { *No se requerirá autorización adicional }\end{array}$ & $\begin{array}{l}\text { Servicios de las plataformas de financiación } \\
\text { participativa }\left(\text { art. } 51^{\circ}\right) \\
\text { a) Recepción, selección y publicación de proyectos } \\
\text { b) Desarrollo, establecimiento y explotación de } \\
\text { canales de comunicación. } \\
\text { * Servicios auxiliares } \\
\text { a) El asesoramiento a los promotores } \\
\text { b) El análisis de los proyectos recibidos, } \\
\text { c) La habilitación de canales de comunicación a } \\
\text { distancia } \\
\text { d) La puesta a disposición de las partes de los } \\
\text { modelos de contratos } \\
\text { e) La transmisión a los inversores de la } \\
\text { información. }\end{array}$ \\
\hline
\end{tabular}




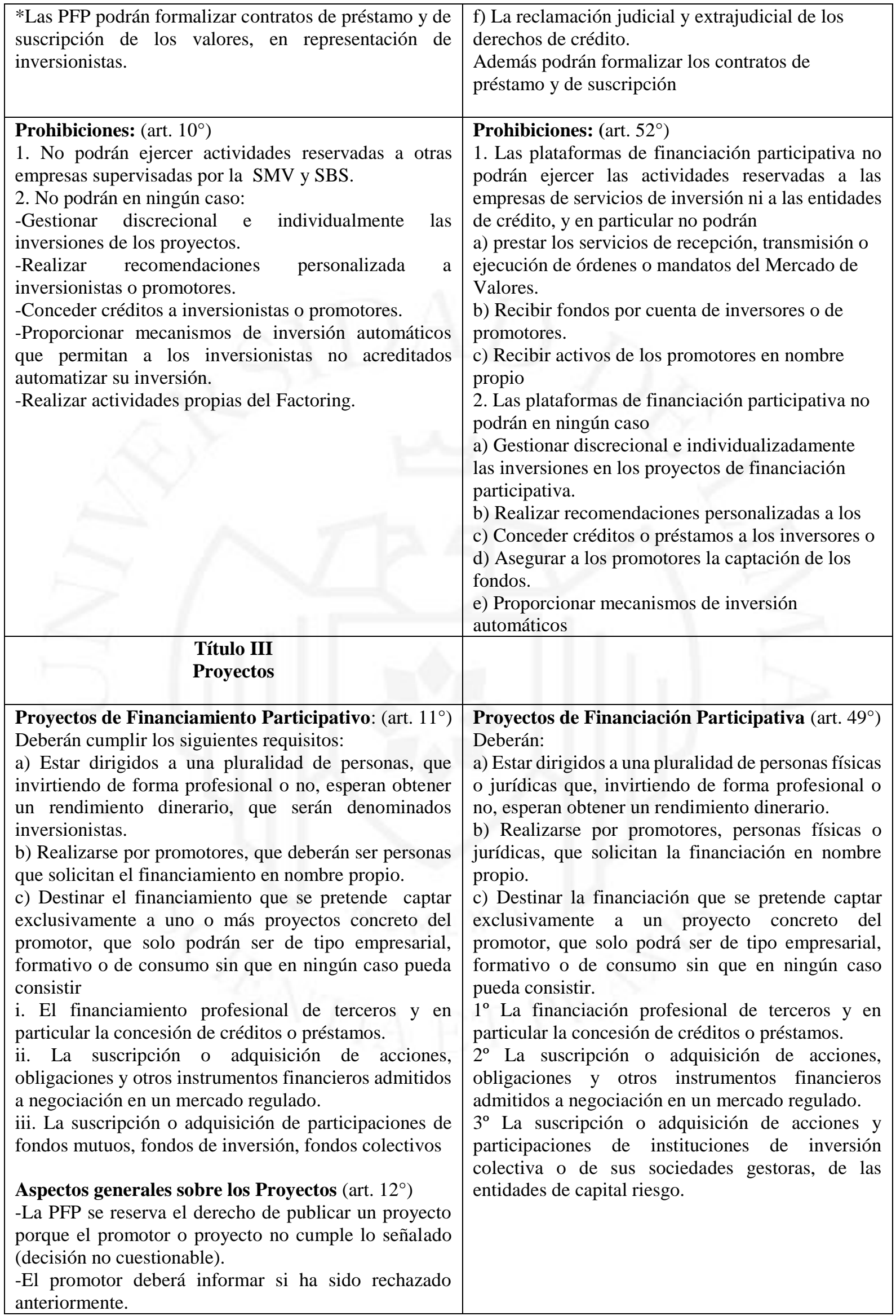




\begin{tabular}{|c|c|}
\hline $\begin{array}{l}\text {-No habrá límite a la cantidad de proyectos que un } \\
\text { mismo promotor publique en una misma PFP. } \\
\text { Información sobre el proyecto }\left(\text { art. } 13^{\circ} \text { ) }\right. \\
\text {-Promotor deberá presentar información veraz del } \\
\text { proyecto } \\
\text { - PFP deberá ofrecer información relevante del } \\
\text { proyecto. } \\
\text { Derecho de Exclusividad (art. } 14^{\circ} \text { ) } \\
\text { Una vez que una PFP haya publicado el Proyecto de un } \\
\text { promotor, el mismo promotor no podrá solicitar a otra } \\
\text { PFP publicar el mismo proyecto. }\end{array}$ & \\
\hline $\begin{array}{l}\text { Responsabilidad }\left(\text { art. } 15^{\circ}\right) \\
\text {-Prohibida la información que induzca a error. } \\
\text {-PFP debe publicar toda la información relevante del } \\
\text { proyecto. } \\
\text {-PFP deberá evaluar la información recibida antes de } \\
\text { publicar. } \\
\text {-Responsabilidad solidaria entre promotor y PFP frente } \\
\text { a inversionista. }\end{array}$ & \\
\hline $\begin{array}{c}\text { Título IV } \\
\text { Modalidades de financiamiento }\end{array}$ & \\
\hline $\begin{array}{l}\text { Modalidades (art. } 16^{\circ} \text { ) } \\
\text { *Financiamiento participativo a través de préstamos: } \\
\text { No tendrá la consideración de captación de fondos } \\
\text { reembolsables del público, dado que los fondos son } \\
\text { otorgados no a la sociedad administradora de la } \\
\text { plataforma sino al promotor. } \\
\text { *Financiamiento participativo a través de valores: } \\
\text { Pueden financiarse a través de la emisión o suscripción } \\
\text { de obligaciones, acciones ordinarias, acciones } \\
\text { preferentes u otros valores. } \\
\text { No tendrá la consideración de oferta pública. } \\
\text { Un proyecto podrá ser financiado con ambas } \\
\text { modalidades de financiamiento. }\end{array}$ & $\begin{array}{l}\text { Formas de financiación participativa. }\left(\text { art. } 50^{\circ} \text { ) }\right. \\
\text { 1. Podrán instrumentarse a través de: } \\
\text { a) La emisión o suscripción de obligaciones, } \\
\text { acciones ordinarias } \\
\text { b) La emisión o suscripción de participaciones de } \\
\text { sociedades de responsabilidad limitada. } \\
\text { c) La solicitud de préstamos. } \\
\text { 2. La solicitud de préstamos a través de la } \\
\text { publicación de proyectos en las plataformas, no } \\
\text { tendrán la consideración de captación de fondos } \\
\text { reembolsables del público. }\end{array}$ \\
\hline $\begin{array}{l}\text { Préstamos }\left(\operatorname{art.} 17^{\circ}\right) \\
\text { 1. Los préstamos concedidos quedarán sujetos al } \\
\text { régimen jurídico al que estén sometidos de acuerdo a los } \\
\text { acuerdos contractuales. } \\
\text { 2. Los proyectos basados en préstamos no podrán } \\
\text { incorporar una garantía hipotecaria sobre la vivienda } \\
\text { habitual del prestatario. }\end{array}$ & $\begin{array}{l}\text { Idoneidad de los préstamos concedidos }\left(\text { art. } 74^{\circ}\right) \\
\text { 1. Los préstamos concedidos quedarán sujetos al } \\
\text { régimen jurídico al que estén sometidos. } \\
\text { 2. Los proyectos basados en préstamos no podrán } \\
\text { incorporar una garantía hipotecaria sobre la } \\
\text { vivienda habitual del prestatario. }\end{array}$ \\
\hline $\begin{array}{l}\text { Valores }\left(\text { art. } 19^{\circ}\right) \\
\text { Las acciones u otros valores representativos de capital y } \\
\text { las obligaciones objeto de la emisión quedarán } \\
\text { sometidos al régimen jurídico que les resulte aplicable. }\end{array}$ & $\begin{array}{l}\left.\text { Idoneidad de los valores emitidos (art. } 77^{\circ}\right) \\
\text { Las acciones, participaciones u otros valores } \\
\text { representativos de capital y las obligaciones objeto } \\
\text { de la emisión quedarán sometidos al régimen } \\
\text { jurídico que les resulte de aplicación y, en su caso, a } \\
\text { lo previsto en la Ley } 24 / 1988 \text {, de } 28 \text { de julio, del } \\
\text { Mercado de Valores, y en el texto refundido de la } \\
\text { Ley de Sociedades de Capital, aprobado por el Real } \\
\text { Decreto Legislativo } 1 / 2010 \text {, de } 2 \text { de julio. }\end{array}$ \\
\hline Fitulo V & \\
\hline
\end{tabular}




\begin{tabular}{|c|c|}
\hline Promotores e inversionistas & \\
\hline $\begin{array}{l}\text { *Promotores }\left(\operatorname{art.} 23^{\circ}\right) \\
\text { Las personas que solicitan financiamiento en nombre } \\
\text { propio y cuyo destino será financiar los proyectos. } \\
\text { No podrán ser promotores: } \\
\text {-Condenados por delitos de terrorismo, tráfico ilícito de } \\
\text { drogas, lavado de activos } \\
\text {-Prohibidos de ejercer el comercio } \\
\text {-Empresas en proceso de insolvencia } \\
\text {-Empresas con deudas } \\
\text {-Miembros de poder legislativo } \\
\text {-Directores, trabajadores y asesores de organismos } \\
\text { públicos }\end{array}$ & $\begin{array}{l}\text { Requisitos de los promotores }\left(\text { Art. } 67^{\circ}\right) \\
\text { 1. El promotor persona jurídica deberá estar } \\
\text { válidamente constituido en España o en otro Estado } \\
\text { miembro de la Unión Europea. En el caso de } \\
\text { personas físicas, su residencia fiscal deberá estar en } \\
\text { España o en otro Estado miembro de la Unión } \\
\text { Europea. } \\
\text { 2. Los promotores o socios de la entidad promotora, } \\
\text { el administrador del promotor o los miembros de su } \\
\text { Consejo de Administración no podrán hallarse } \\
\text { inhabilitados conforme a lo previsto en la Ley } \\
\text { 22/2003, de } 9 \text { de julio, Concursal, o normativa } \\
\text { equivalente de otros Estados miembros de la Unión } \\
\text { Europea, ni podrán estar cumpliendo condena por la } \\
\text { comisión de delitos o faltas contra el patrimonio, el } \\
\text { blanqueo de capitales, el orden socioeconómico, la } \\
\text { Hacienda Pública y la Seguridad Social. }\end{array}$ \\
\hline $\begin{array}{l}\text { *Inversionistas }\left(\text { art. } 24^{\circ}\right) \\
\text { Personas naturales o jurídicas que otorgan el } \\
\text { financiamiento a los promotores bajo alguna de las } \\
\text { modalidades. } \\
\text {-Acreditados } \\
\text {-No Acreditados }\end{array}$ & $\begin{array}{l}\text { Tipos de inversores (art. 81) } \\
\text { 1. Los inversores podrán ser acreditados o no } \\
\text { acreditados. }\end{array}$ \\
\hline Normas Adicionales & Normas de Conducta \\
\hline $\begin{array}{l}\text { *Principios Generales }\left(\text { art. } 28^{\circ}\right) \\
\text {-Equidad } \\
\text {-Prioridad de intereses } \\
\text {-Competencia } \\
\text {-Honestidad, cuidado y diligencia } \\
\text {-Información a los clientes } \\
\text {-Objetividad y prudencia } \\
\text {-Observancia }\end{array}$ & $\begin{array}{l}\text { Principios Generales (art. 60) } \\
\text { 1. Las plataformas de financiación participativa } \\
\text { deberán ejercer su actividad de acuerdo con los } \\
\text { principios de neutralidad, diligencia y trasparencia y } \\
\text { con arreglo al mejor interés de sus clientes. } \\
\text { 2. Tendrán la consideración de clientes tanto los } \\
\text { promotores como los inversores. } \\
\text { 3. La información que proporcionen a sus clientes } \\
\text { sobre los derechos y obligaciones que asumen al } \\
\text { operar a través de la plataforma de financiación } \\
\text { participativa deberá ser clara, oportuna, suficiente, } \\
\text { accesible, objetiva y no engañosa. }\end{array}$ \\
\hline $\begin{array}{l}\text { *Obligaciones de información general (art. } 29^{\circ} \text { ) } \\
\text { Las PFP deberán incluir la siguiente información: } \\
\text {-Funcionamiento básico } \\
\text {-Advertencia de riesgos } \\
\text {-Advertencia de que la PFP no ostenta la condición de } \\
\text { empresa de servicios } \\
\text {-Advertencia de que los proyectos no son objeto de } \\
\text { autorización ni supervisión de SMV }\end{array}$ & $\begin{array}{l}\text { *Obligaciones de información general }\left(\text { art. } 61^{\circ} \text { ). }\right. \\
\text { Las PFP deberán incluir la siguiente información: } \\
\text { a) El funcionamiento básico de la plataforma. } \\
\text { b) Advertencia de los riesgos } \\
\text { c) La advertencia de que la plataforma no ostenta la } \\
\text { condición de empresa de servicios de inversión, ni } \\
\text { entidad de crédito } \\
\text { d) La advertencia de que los proyectos no son objeto } \\
\text { de autorización ni de supervisión por la Comisión } \\
\text { Nacional del Mercado de Valores ni por el Banco de } \\
\text { España. }\end{array}$ \\
\hline $\begin{array}{l}\text { *Conflictos de interés }\left(\operatorname{art} .30^{\circ}\right) \\
\text { Las PFP establecerán y aplicarán una política efectiva } \\
\text { en materia de conflictos. Se hará pública en su página } \\
\text { web y se ajustará al tamaño de la organización }\end{array}$ & $\begin{array}{l}\text { *Conflictos de interés }\left(\operatorname{art} .62^{\circ}\right) \\
\text { Las plataformas de financiación participativa } \\
\text { establecerán y aplicarán una política efectiva en }\end{array}$ \\
\hline
\end{tabular}




\begin{tabular}{|c|c|}
\hline & $\begin{array}{l}\text { materia de conflictos de interés. Dicha política se } \\
\text { hará pública en su página web. }\end{array}$ \\
\hline Supervisión SMV & Supervisión, inspección y sanción \\
\hline $\begin{array}{l}\text { Competencia de la SMV (art. } 33^{\circ} \text { ) } \\
\text { Las PFP están sujetas a la supervisión de la SMV. En tal } \\
\text { sentido, es la SMV encargada de aplicar sanciones } \\
\text { Régimen e Infracciones (art. } 34^{\circ} \text { y } 35^{\circ} \text { ) } \\
\text { La SMV es la encargada de aplicar las sanciones }\end{array}$ & $\begin{array}{l}\text { Régimen de inspección y sanción (art. 89) } \\
\text { 1. Quedan sujetos al régimen de supervisión, } \\
\text { inspección y sanción de este título, a cargo de la } \\
\text { Comisión Nacional del Mercado de Valores }\end{array}$ \\
\hline
\end{tabular}

$\mathrm{Al}$ respecto, tenemos tres observaciones que señalar: la primera, se refiere a la definición del crowdfunding y sus modalidades. Somos de la opinión que el referido Proyecto de Ley deberá otorgar una explicación más detallada de lo que significa el crowdfunding y sus modalidades, con la finalidad de mostrar a los emprendedores otras alternativas de financiamiento distintas al equity crowdfunding y crowdlending. La segunda, es que el proyecto de Ley no considera como requisito para solicitar su inscripción ante el ente regulador contar con un Reglamento Interno de Conducta, tal como lo considera la norma española. A nuestro parecer, el proyecto de Ley deberá señalar la obligación de las plataformas de contar con un Reglamento Interno de Conducta previo a la presentación de solicitud de inscripción, pues la consideramos como un compromiso de respeto y ética en el ámbito financiero, así como una forma de autorregulación. La tercera, es que el proyecto de Ley no contempla los casos en que las autorizaciones de las plataformas podrán ser objeto de revocación o suspensión, como sí lo señala la norma española.

\subsubsection{Proyecto de Ley N. ${ }^{\circ}$ 3403/2018-CR:}

El 18 de setiembre de 2018 la congresista Lourdes Alcorta Suero, presentó ante el Congreso el Proyecto de Ley N. ${ }^{\circ}$ 3403-2018-CR, "Ley que declara de interés nacional y necesidad pública la regulación de la tecnología financiera (Fintech)", la cual desde el 21 de setiembre de 2018 se encuentra en la Comisión Economía, Banca, Finanzas e Inteligencia Financiera del Congreso.

Esta iniciativa legislativa propone que se declare de interés nacional y necesidad pública la regulación de la tecnología financiera (Fintech) con el objetivo de proteger el interés de los usuarios. Como lo señala la exposición de motivos, las fintech traen consigo 
beneficios y retos, por ello, el Estado deberá asegurar que su desarrollo no afecte al sistema financiero.

\subsubsection{Proyecto de Ley $\mathrm{N}^{\circ}{ }^{4324 / 2018-P E}$}

La Comisión de Economía, Banca Finanzas e Inteligencia Financiera recomendó la aprobación de los Proyectos de Ley N. ${ }^{\circ} 3083 / 2017-C R, ~ N .^{\circ} 3403 / 2018-$ CR y N. ${ }^{\circ} 4324 / 2018-P E$ con el texto sustitutorio del Proyecto de Ley N. ${ }^{\circ} 4324 / 2018-P E$.

Es necesario señalar que los objetivos de los mencionados proyectos son: Proyecto de Ley 3083/2017-CR, regular las Plataformas de Financiamiento Participativo, esto es, delinear los límites de inclusión de la norma a aquellas Plataformas que ponen en contacto a un conjunto de inversionistas, ya sean estos personas naturales o jurídicas con personas que necesiten y requieran de un financiamiento para sus proyectos y cuyo medio de contacto sea por páginas web u otro electrónico; Proyecto de Ley 3403/2018-CR, declarar de interés nacional y necesidad pública la regulación de la tecnología financiera; y el Proyecto de Ley 4324/2018-PE, establecer el marco jurídico de la actividad de financiamiento participativo financiero, además de las sociedades autorizadas para administrar las plataformas a través de las cuales se realiza dicha actividad. (Dictamen del proyecto de Ley N. ${ }^{\circ}$ 3083/2017-CR, 3403/2018-CR t 4324/2018-PE, 2018, pp. 1-2).

El dictamen favorable sustitutorio recoge las opiniones recibidas de diversas entidades:

OPINIONES RESPECTO AL PROYECTO DE LEY N. ${ }^{\circ}$ 3083/2017-CR

\begin{tabular}{l|l|l|l} 
PCM & MEF & BCRP & SBS \\
\hline
\end{tabular}




\begin{tabular}{|c|c|c|c|}
\hline $\begin{array}{l}\text { "Requiere desarrollar el } \\
\text { concepto de crowdfunding } \\
\text { financiero e incorporar como } \\
\text { requisito que las PFP tengan un } \\
\text { capital mínimo para acreditar } \\
\text { solvencia" }\end{array}$ & $\begin{array}{l}\text { "Precisar que el } \\
\text { financiamiento } \\
\text { participativo a } \\
\text { través de préstamo } \\
\text { no es considerado } \\
\text { intermediación } \\
\text { financiera" }\end{array}$ & $\begin{array}{l}\text { "Incluir que las } \\
\text { PFP } \\
\text { normas observen } \\
\text { lavado de activos, } \\
\text { financiamiento al } \\
\text { terrorismo y de } \\
\text { protección } \\
\text { datos. Establecer } \\
\text { mecanismos para } \\
\text { facilitar } \\
\text { inversionistas que } \\
\text { identifique al } \\
\text { promotor sobre el } \\
\text { cual tiene derecho } \\
\text { de cobro para } \\
\text { tomar acciones por } \\
\text { incumplimiento" }\end{array}$ & \begin{tabular}{|lr} 
"Implementar & el \\
esquema r & de \\
SANBOX, contar \\
con herramientas \\
regulatorias & frente \\
a los r nuevos \\
modelos r \\
negocios r de \\
surgen que \\
consecuencias de \\
las romo \\
tecnologías, nuevas \\
otorgando r \\
facultades para que \\
la SMV y la SBS \\
puedan establecer \\
ámbitos r de \\
regulación"
\end{tabular} \\
\hline
\end{tabular}

(Dictamen del Proyecto de Ley N. ${ }^{\circ}$ 3083/2017-CR, 3403/2018-CR t 4324/2018-PE, 2018, pp. 3-4).

Podemos destacar la opinión de la Superintendencia de Banca, Seguros y AFP (SBS) pues señala que debe implementarse el esquema de Sanbox, siendo esta una oportunidad que otros países la han implementado, de tal manera que se pueda contar con herramientas regulatorias para emplearla en caso aparezcan nuevas tecnologías, y así se puede utilizar temporalmente y bajo supervisión de la SMV operaciones o actividades con flexibilidad regulatoria.

Si bien es cierto en el proyecto de Ley $\mathrm{N}^{\circ}$ 4324/2018-PE incluye en las Disposiciones Complementarias Finales, en el punto Quinto, como Nuevos Modelos SMV, no lo desarrolla como lo hace México o Colombia; sin embargo, deja la puerta abierta a futuros modelos bajo supervisión de la SMV, brindándole facultades para otorgar excepciones a la regulación que resulte aplicable.

En el punto VI del Dictamen Favorable Sustitutorio, clasifica al Financiamiento Participativo en dos grupos: los Financieros y no Financieros, excluyendo dentro de la necesidad de regular, a este último. Se utiliza el criterio del retorno financiero asociado, protegiendo a los inversionistas, esquema que no cumplen con la recompensa o donación, 
ya que los aportantes lo hacen con fines benéficos, gratuitos o por la adquisición de un bien.

Por otro lado, el Dictamen Favorable Sustitutorio encuentra una serie de beneficios a la propuesta, que mencionamos a continuación:

- Establecer un marco legal para el desarrollo del financiamiento participativo

- Promover la inclusión financiera de ciudadanos y pequeñas empresas, financiando emprendimientos

- Transformar los servicios financieros mediante la utilización de nuevas tecnologías

- Mejorar la accesibilidad y sencillez de los servicios financieros

- Disminuir los costos de transacción al utilizar la tecnología en los servicios financieros

- $\quad$ Reducir los fraudes financieros, lavado de activos, financiamiento de actividades ilícitas, entre otros.

- Dinamizar la economía mediante el impulso de las inversiones que se desarrollen a través de estos nuevos mecanismos de financiamiento" (Dictamen del Proyecto de Ley N. ${ }^{\circ}$ 3083/2017-CR, 3403/2018-CR t 4324/2018-PE, 2018, pp. 11-12).

Respecto a las observaciones realizadas en este trabajo de investigación al Proyecto de Ley N. ${ }^{\circ} 3083 / 2017-C R$, podemos afirmar lo siguiente: que el texto sustitutorio del Proyecto de Ley N. ${ }^{\circ}$ 4324/2018-PE, delimita su ámbito de aplicación sólo para el equity crowdfunding y lending crowdfunding. Por otro lado, incluye la obligación de las plataformas de financiamiento participativo financiero de remitir sus reglamentos internos a la SMV para su aprobación, por lo que consideramos que ante estas obligaciones señaladas, las sociedades administradoras deberán adecuar sus actividades dentro del marco del Buen Gobierno Corporativo; así también, señala la obligación de suministrar a la SMV la información de sus actividades y gestión; por otro lado, el Proyecto de Ley no señala los principios generales para el desarrollo de sus actividades solo señala que las funciones de las sociedades administradoras de plataformas deberán realizar sus funciones con diligencia, lealtad e imparcialidad, dejando de lado los demás principios considerados en el Proyecto de Ley 3083.

Una de las novedades que contiene el proyecto de Ley 4324/2018-PE, y que consideramos muy acertada, es catalogar a las sociedades administradoras de plataformas de financiamiento participativo financiero como sujetos obligados a proporcionar 
información a la UIF e implementar un sistema de prevención de LAFT. Asimismo, les prohíbe recibir en las cuentas donde se gestione los recursos propios de la sociedad administradora, fondos de los receptores o inversionistas, obtenidos como consecuencia del ofrecimiento de valores o préstamos, salvo por las comisiones de sus servicios. Por otro lado, les prohibe participar directa o indirectamente como receptores o inversionistas en proyectos del financiamiento participativo financiero.

\subsubsection{Proyecto de Ley ${ }^{\circ}{ }^{\circ} 4421 / 2018-C R$}

El Proyecto de Ley N. ${ }^{\circ} 4421-2018-C R$ — proyecto Ley que norma el desarrollo de la tecnología financiera en el Perú-, es una iniciativa de la congresista Marisol Espinoza Cruz, presentado el 5 de junio de 2019, mediante el cual se dispone que la Superintendencia de Mercado de Valores (SMV) sea la entidad estatal encargada de autorizar, registrar, regular, supervisar y fiscalizar el desarrollo de la tecnología financiera en nuestro país. Asimismo, faculta a la Superintendencia de Mercado de Valores (SMV) a: realizar las coordinaciones sus actividades con otras entidades como SBS, Sunat, Indecopi, BCR y UIF; <solicitar información a las empresas nacionales o extranjeras que operen a través de las oferta de tecnología financiera con la finalidad de conocer y hacer seguimiento sus actividades; y emitir directivas, medidas, sanciones, entre otros. (Proyecto de Ley N. ${ }^{\circ} 4421 / 2018-C R, 2018$, pp. 1-2).

\subsection{Desregularización:}

La expresión denota cierta ambigüedad, pero tal vez convenga señalar que, no alude a la ausencia de normas, sino a un peculiar estilo de producción normativa, caracterizado por una reducción de normas de carácter público e intervencionista, que contrasta con la relevancia que el propio Estado por diversas vías concede a la autonomía normativa del sector privado. La desregulación, no se identifica, empero, con la anomia, sino con la sustitución de una legislación intervencionista, que adopta medidas políticas para influir y modificar las estructuras sociales y económicas, por otra abstencionista, tolerante con las normas procedentes de los propios agentes económicos y sociales, y limitada a garantizar la vigencia de las reglas de juego del libre 
mercado, en especial la libre competencia o igualdad de oportunidades entre sujetos económicos privados (Marcilla, 2005, p. 246).

Compartimos la opinión de Marcilla (2005) al considerar la desregulación como una forma de producción normativa que favorece a una mejor prestación de servicios a la sociedad (p. 241).

\subsubsection{Autorregulación}

“Consiste en la ordenación de aspectos básicos del funcionamiento del mercado a través de decisiones que excluyen a los poderes públicos, pues parten de los mismos operadores económicos que actúan en el mercado" (Marcilla, 2005, p. 247).

La definición de Marcilla (como se citó en Darnaculleta, M., 2002) "consiste en la actividad privada de producción y control de normas bajo la responsabilidad de quienes las elaboran, aplican o controlan, se inspira en la lex artis (pautas de conducta adecuadas en el quehacer cotidiano de una actividad que requiere la aplicación de ciertos conocimientos científicos, técnicos o éticos o grado de especialización)” (p. 247).

Las categorías para Marcilla (como se citó Pardo, E., 2004), son tres:

- Pautas normativas con cierto grado de abstracción (normas técnicas, protocolos o códigos de conducta)

- Acuerdos o decisiones singulares

- Vías de solución de conflictos (arbitraje o mediación)

\subsubsection{Autorregulación Regulada:}

Como señala Marcilla (2005):

La autorregulación regulada representa una especie dentro del género desregulación, que consiste en la tolerancia por parte de los poderes públicos, de las normas gestadas en el ámbito privado, pero con el objetivo de tales normas sirvan a cumplir fines de interés general (p. 247).

Sobre la base de lo antes mencionado, Marcilla (2005) expresa que "las autoridades estatales aceptan las normas gestadas en el ámbito privado, pero con el objetivo de servirse luego de ellas para cumplir fines públicos”. Por ello, precisa que la 
característica de la regulación es la cooperación entre Estado y sujetos privados, con el objetivo de cumplir los intereses generales" (p. 248).

Se trata de un método de regulación indirecta: el Estado renuncia a establecer por sí mismo el régimen jurídico de algunas materias (especialmente aquellas de elevada complejidad técnica o que plantean problemas éticos) aunque previamente disciplina el contexto en el que ha de tener lugar la actividad normativa de los sujetos privados (contenido mínimo de la regulación o requisitos que debe cumplir, órganos encargados de elaborarlas, los efectos públicos de las mismas), asumiendo los resultados de éstos últimos, esto es, los instrumentos de regulación gestados en el ámbito privado, tales como códigos deontológicos, códigos de comportamiento, normas técnicas (Marcilla, 2005, p. 248).

Como se puede apreciar, las iniciativas legislativas que se encuentran pendientes de debate ante el Congreso de la República comprenden el marco legal general del crowdfunding. Por tal razón, proponemos que, en el marco de la autorregulación regulada, las empresas administradoras de la plataforma desarrollen una norma que disponga parámetros y/o principios como una especie de Código de Conducta, el dual deberá ser considerado por todas las empresas que administren plataformas y desarrollen crowdfunding.

Dicho planteamiento correspondería a lo manifestado por Marcilla (2005) cuando se refiere a que son los propios sujetos económicos quienes mejor conocen sus necesidades e intereses y por ello, optan por la autonormación (p. 258).

\subsection{Propuesta de Autorregulación para el Perú:}

En el Perú, el crowdfunding aún no cuenta con un desarrollo normativo promulgado, ya que las iniciativas legislativas presentadas aún se encuentran en debate ante el Congreso. En tal sentido, sugerimos que las empresas que administran las plataformas colaborativas puedan asociarse y autorregularse mediante el establecimiento de un Código de Conducta que brinde los parámetros de acción y/o principios generales para el desarrollo de cualquier tipo de crowdfunding, como fue el caso de México, donde las plataformas formaron la Asociación de Plataformas de Fondeo Colectivo (Afico), antes que la Ley 
para Regular las Instituciones de Tecnología Financiera fuera promulgada, fijando como su principal objetivo proteger el interés general y distinguirse como empresas comprometidas (Padilla, 2017, párr. 3-5).

Atendiendo a lo descrito, sugerimos que esta forma de autorregulación puede establecerse dentro del marco del Buen Gobierno Corporativo, lo cual permitirá a las empresas administradoras de las plataformas estructurar su organización interna en base a la ética y transparencia, logrando con ello la cooperación con el Estado, lo que conllevará a la sostenibilidad y a la maximización del valor de las empresas dedicadas al crowdfunding.

\subsubsection{Gobierno Corporativo y Buen Gobierno Corporativo:}

Iniciamos esta sección señalando que las corrientes del Gobierno Corporativo y el Buen Gobierno Corporativo, no son sinónimos.

El Gobierno Corporativo es definido como:

Un sistema dentro de la sociedad empresarial, que incluye procedimientos, actividades (prácticas) e instituciones (normas). Este sistema está referido a la relación entre accionistas de la sociedad y su administración. Esta relación está definida en términos de derechos, potestades y responsabilidades de cada grupo. Esto es, tiene que ver con la estructura de las sociedades empresariales y las vinculaciones entre sus elementos (Martínez, 2007, p. 20).

Por otro lado, el Buen Gobierno Corporativo consiste en "el requerimiento que realizan ciertos accionistas a los administradores de las Corporations para que voluntariamente mejoren en sus documentos de constitución, estatutos y reglamentos, el tratamiento a los accionistas y reconozcan los intereses que a éstos les corresponde" (Martínez, 2007, p. 35).

En tal sentido, citamos lo indicado por Conde (2007):

El Gobierno Corporativo se refiere a la forma en que se dirigen y controlan las sociedades y refleja las relaciones de poder entre los accionistas y la gerencia y otros grupos de interés, en cambio un Buen Gobierno Corporativo se compone de estándares mínimos adoptados por una sociedad y el propósito que tiene como 
es: contar con una recta gerencia, reconocer el derechos de los accionistas, definir responsabilidades del directorio (pp.41-42).

Es en este contexto surgen los denominados Principios de Buen Gobierno Corporativo entendidos como "el conjunto de estándares que acogen las sociedades mercantiles en aras de adquirir una mayor transparencia, credibilidad y valor agregado ante potenciales inversionistas" (López, 2012, p. 315).

Como lo señala Hundskopf (2004) "los Principios de Buen Gobierno Corporativo no son vinculantes: únicamente tienen carácter de recomendación en todos los países en que existen, más los principales aspectos de independencia sin son recogidos por la legislación societaria, como en el Perú” (p. 45).

Asimismo, señala que "el Buen Gobierno Corporativo busca evitar: la falta de transparencia en la información que se proyecta al mercado, información asimétrica, contabilidad creativa" (Hundskopf, 2004, p. 44).

En el 2002, la Superintendencia del Mercado de Valores (SMV) y otras entidades públicas, se integraron en un Comité y emitieron un documento que contiene los "Principios de Buen Gobierno para las Sociedades Peruanas" teniendo como temas más importantes los derechos y tratamiento equitativos de los accionistas, transparencia, responsabilidades del Directorio. Posteriormente se desarrolla el "Código de Buen Gobierno Corporativo para las Sociedades Peruanas", exigibles solo para las empresas que listan en la Bolsa de Valores (SMV - Código de Buen Gobierno Corporativo, 2002, p. 6).

Uno de los Principios del Código del Buen Gobierno Corporativo para las empresas Peruanas es el denominado "Principio 22: Código de Ética y Conflictos de Interés". Mediante este principio se exige el cumplimiento de comportamientos éticos al directorio, gerentes, funcionarios y demás colaboradores de la sociedad.

Por lo expuesto, la medida de autorregulación que deben emplear las empresas administradoras de plataformas debe estar en el marco del Buen Gobierno Corporativo basado en principios generales, que permitirá la creación de manuales de procedimientos que dirijan su accionar.

\subsubsection{Principios Generales:}


Con la finalidad de establecer principios generales que sirvan de base para una adecuada autorregulación, haremos mención a diversos hechos que en nuestra opinión pueden colaborar con la promoción de la autorregulación para las empresas de crowdfunding y fintech.

En primer lugar, hacemos referencia a la Alianza del Pacífico considerada "un mecanismo de articulación política, económica, de cooperación e integración que busca encontrar un espacio para impulsar un mayor crecimiento y mayor competitividad de las cuatro economías que la integran”, conformada por cuatro países: Chile, Colombia, México y Perú (Alianza del Pacífico, 2019, párr. 1).

El 7 de julio de 2018 se realizó en Colombia la XVII Reunión de Ministros de Finanzas de la Alianza del Pacífico, donde resaltaron la importancia de la regulación Fintech y anunciaron establecer unos principios rectores que fomenten la discusión y el desarrollo de actividades Fintech en los países de la Alianza (Alianza Pacífico, 2017, párr. 4).

Así, el Consejo de Ministros de Finanzas presentó los Principios Orientadores para la regulación Fintech en la Alianza del Pacífico, con la finalidad que sirva a los países miembros para que trabajen coordinadamente basados en principios comunes (MEF, 2018, párr. 7).

En segundo lugar, tenemos a la Ley para Regular las Instituciones de Tecnología Financiera promulgada en México el 9 de marzo de 2018, en cuyo artículo $2{ }^{\circ}$ señala los principios en los que se basa la referida Ley.

Por otro lado, tenemos a la Alianza Fintech Iberoamérica fundada en el 2017 que tiene como objetivo fomentar el "desarrollo del ecosistema fintech en toda la región y aprovechar las mejores prácticas internacionales" (García de la Cruz, 2017, párr. 1).

Es necesario señalar que la Alianza Fintech Iberoamérica está conformada por países de Centro América y el Caribe, y por Colombia, España, México, Panamá, Portugal, Perú y Uruguay, y que en el 2018 desarrollaron la II Cumbre de la Alianza Fintech Iberoamérica a iniciativa de la Asociación Española de Fintech e InsurTech (AEFI) (Revista +Finanzas, 2018, párr. 1).

De acuerdo con lo señalado en el Resumen Informe Fintech en América Latina (2018), entre los logros obtenidos desde su fundación se señala la creación de un 
Decálogo de Buenas Prácticas, el cual tuvo como base el Código de Buenas Prácticas para las Fintech y las Insurtech de España (p. 101).

Atendiendo a lo descrito, hemos elaborado a modo de resumen un cuadro comparativo que recoge los principales principios orientados para crowdfunding y fintech propuestos en los mencionados documentos internacionales:

\begin{tabular}{|c|c|c|}
\hline $\begin{array}{c}\text { ALIANZA PACÍFICO } \\
2017-2018\end{array}$ & MÉXICO 2018 & $\begin{array}{l}\text { ALIANZA FINTECH } \\
\text { IBEROAMÉRICA } \\
2018\end{array}$ \\
\hline $\begin{array}{c}\text { Principios Orientadores para la } \\
\text { regulación Fintech en la } \\
\text { Alianza del Pacífico }\end{array}$ & $\begin{array}{c}\text { Ley para Regular las } \\
\text { Instituciones de Tecnología } \\
\text { Financiera }\end{array}$ & $\begin{array}{c}\text { Código de Buenas Prácticas } \\
\text { para las Fintech y las } \\
\text { Insurtech de España }\end{array}$ \\
\hline $\begin{array}{l}\text { - Flexibilidad. } \\
\text {-Regulación por actividades. } \\
\text {-Neutralidad tecnológica. } \\
\text {-Proporcionalidad basada en } \\
\text { riesgos. } \\
\text {-Protección al consumidor. } \\
\text {-Integridad y estabilidad } \\
\text { financiera. } \\
\text {-Prevención de riesgos de lavado } \\
\text { de activos y financiación del } \\
\text { terrorismo. } \\
\text {-Coordinación y cooperación. }\end{array}$ & $\begin{array}{l}\text {-Inclusión e innovación } \\
\text { financiera. } \\
\text {-Promoción de la } \\
\text { competencia. } \\
\text {-Protección al consumidor. } \\
\text {-Preservación de estabilidad } \\
\text { financiera. } \\
\text {-Prevención de operaciones } \\
\text { ilícitas. } \\
\text {-Neutralidad tecnológica. }\end{array}$ & $\begin{array}{l}\text {-Valores de la Asociación: } \\
\text { *Transparencia. } \\
\text { *Colaboración. } \\
\text { *Comunicación. } \\
\text { *Investigación. } \\
\text {-Obligaciones éticas y legales. } \\
\text {-Obligaciones en sus relaciones } \\
\text { con los clientes. } \\
\text {-Obligaciones en el análisis y } \\
\text { prestación de los servicios y en } \\
\text { su actuación en el mercado. } \\
\text {-Obligaciones en la página web. }\end{array}$ \\
\hline
\end{tabular}

\begin{tabular}{|c|c|c|}
\hline ESPAÑA & MÉXICO & PERÚ \\
2015 & 2014 & 2018 \\
\hline Ley 5/2015 & Asociación de Plataforma de & Proyecto de Ley N. ${ }^{\circ}$ 3083/2017- \\
Ley de Fomento de la & Fondeo - AFICO & CR \\
Financiación Empresarial & & \\
\hline
\end{tabular}




\begin{tabular}{|l|l|l|}
\hline -Neutralidad. & a) Cumplimiento de Leyes y & -Equidad. \\
-Diligencia. & regulaciones. & -Prioridad. \\
-Trasparencia. & 1.- Discriminación. & -Competencia. \\
& 2.- Protección de datos & personales. \\
& 3.- Equidad. & -Honestidad, cuidado y diligencia. \\
& b) Responsabilidad de & -Información a los clientes. \\
& Transparencia. & -Objetividad y prudencia. \\
& c) Conflicto de interés. & -Observancia. \\
& 1.- Violación del Código. & \\
& 2.- Regulación. & \\
& d) Confidencialidad. \\
& e) Política Anti Plagio. \\
& f) Seguridad. & \\
& g) Profesionalismo.
\end{tabular}

\subsubsection{Propuesta de Código de Conducta para Plataformas en el Perú:}

Teniendo como base los documentos internacionales mencionados a lo largo de este capítulo, proponemos establecer un Código de Conducta de carácter obligatorio para todas las plataformas que desarrollen crowdfunding en nuestro país, el cual esté basado en los principios generales que a continuación detallaremos.

A continuación segmentamos los campos de acción y precisamos los principios rectores que servirán de base para establecer un Código de Conducta que permitirá el desarrollo del crowdfunding:

\begin{tabular}{|c|c|c|}
\hline ASPECTO & PRINCIPIOS & ACCIÓN \\
\hline $\begin{array}{l}\text { Sistema } \\
\text { Financiero }\end{array}$ & $\begin{array}{l}\text {-Preservación de la estabilidad } \\
\text { financiera. }\end{array}$ & $\begin{array}{l}\text { *En ningún caso podrán desempeñar } \\
\text { actividades reservadas a los entes } \\
\text { reguladores. } \\
\text { *Desarrollar sus actividades garantizando } \\
\text { la seguridad jurídica y el respecto al interés } \\
\text { público. }\end{array}$ \\
\hline
\end{tabular}




\begin{tabular}{|c|c|c|}
\hline Tecnología & $\begin{array}{l}\text {-Inclusión e innovación financiera; } \\
\text { Promoción de la investigación. }\end{array}$ & $\begin{array}{l}\text { *Promover la investigación apoyando la } \\
\text { difusión de los proyectos. } \\
\text { *Facilitar a los emprendedores los servicios } \\
\text { necesarios para alcanzar su financiamiento. } \\
\text { *Garantizar la seguridad informática de las } \\
\text { páginas web, a fin de prevenir ataques o } \\
\text { robo de información. }\end{array}$ \\
\hline $\begin{array}{l}\text { Plataformas } \\
\text { (como } \\
\text { empresas) }\end{array}$ & $\begin{array}{l}\text {-Proporcionalidad; Promoción de la } \\
\text { competencia; Colaboración. }\end{array}$ & $\begin{array}{l}\text { *Fomentar la colaboración y la libre } \\
\text { competencia entre las Plataformas. }\end{array}$ \\
\hline $\begin{array}{l}\text { Usuarios } \\
\text { (inversores } \quad y \\
\text { promotores) }\end{array}$ & $\begin{array}{l}\text {-Protección al consumidor; } \\
\text { Transparencia; Comunicación; } \\
\text { Diligencia. } \\
\text { - Equidad; Discriminación. } \\
\text {-Confidencialidad; Protección de } \\
\text { datos personales }\end{array}$ & $\begin{array}{l}\text { *Fomentar un canal de comunicación, a fin } \\
\text { de canalizar reclamos. } \\
\text { *Brindar información verás respecto a los } \\
\text { proyectos. } \\
\text { *Desempeñar sus actividades con la debida } \\
\text { diligencia requerida. } \\
\text { *Tratar por igual y sin discriminación a los } \\
\text { diversos usuarios. } \\
\text { *Respetar la confidencialidad cuando los } \\
\text { promotores señalen la información } \\
\text { confidencialidad de los proyectos. } \\
\text { *Cumplir la normativa nacional } \\
\text { correspondiente a la protección de datos de } \\
\text { sus inversores y promotores. }\end{array}$ \\
\hline Compliance & -Prevención de operaciones ilícitas. & $\begin{array}{l}\text { *Instaurar un sistema preventivo de riesgos } \\
\text { e implementar una cultura de } \\
\text { cumplimiento. } \\
\text { * Registrarse en el Registro de Plataforma } \\
\text { de Participación Colaborativa del ente } \\
\text { regulador. } \\
\text { *Contar con un Reglamento Interno de } \\
\text { Conducta, que establezca obligaciones de } \\
\text { sus órganos. }\end{array}$ \\
\hline
\end{tabular}




\begin{tabular}{|l|l|l|}
\hline -Obligaciones en la página web. & $\begin{array}{l}\text { *Poner a disposición a los futuros } \\
\text { inversores y promotores información } \\
\text { relativa a la Plataforma como son sus: } \\
\text { miembros, objetivos, proyectos, términos y } \\
\text { condiciones, casos de éxito, guía de } \\
\text { registro, forma de contacto. }\end{array}$ \\
\end{tabular}

\subsubsection{Sandbox Regulatorio:}

Debemos comenzar indicando ¿qué es un Sandbox Regulatorio?, este innovador concepto nació en el año 2016 en Inglaterra y viene siendo implementado en diversos países de Europa, como es el caso de España y en Latinoamérica, como son los casos de México y Colombia.

De acuerdo con lo señalado por el BBVA (2017) el Sandbox viene a ser "un entorno seguro en el que las Fintech se van adaptando progresivamente a los muchos requerimientos de la actividad financiera" (párr. 4).

Se trata de incentivar la competencia y la innovación financiera controlando los riesgos y evitando que afecten al consumidor final. Las Fintech van avanzando en sus procesos, cumpliendo poco a poco con todas las regulaciones, y al final del camino dejan ese campo de pruebas para competir con el resto de las entidades financieras, ya sin red de seguridad (BBVA, 2017, párr. 5).

Por su parte. Vodanovic Legal (2018), describe al Sandbox como:

Se trata de una regulación de prueba pensada especialmente para que nuevos emprendimientos puedan gozar de una plataforma experimental y un marco regulatorio que les permita probar temporalmente nuevos productos, servicios y modelos de negocio regulados antes de sus lanzamientos al mercado sin pasar por el procedimiento formal, y en ocasiones excesivo, de obtención de licencias que caracteriza a las actividades reguladas $\mathrm{s}$; y sin incurrir en riesgos de incumplimiento normativo traducidos en la imposición multas y/o sanciones de otra índole (cierre y/o suspensión de actividades, amonestaciones, etc.) (p.63)

En una entrevista hecha a Álvaro Martín, jefe de Regulación Digital y Tendencias del BBVA Research (2018), a la pregunta, ¿pueden los sandboxes marcar el paso el 
regulador? Le van a servir al regulador para entender mejor qué debe regular, qué no y tener más tiempo de respuesta".

El sandbox adelanta ese punto de contacto entre los innovadores y las autoridades para que comprueben si los modelos y las tecnologías que quieren aplicar tienen una respuesta adecuada entre los clientes, si son capaces de hacer una operación que tenga sentido comercialmente en el momento en el que deban cumplir con toda la regulación aplicable (párr. 6)

Implementar un Sandbox en el Perú sería una alternativa ingeniosa que nos permitiría tener una mejor coordinación entre entidades encargadas de llevar y supervisar el desarrollo de la Fintech y el sector privado, ya que, con este sistema, estaríamos incentivando la participación de ideas originales para el sistema financiero, sin tener limitaciones por vacíos legales, pero con una supervisión por parte del Estado con el objetivo de crear competencia y satisfacer necesidades del consumidor final que muchas veces no se llega.

En la actualidad, en España se ha publicado el Anteproyecto de Ley de Medidas para la Transformación Digital del Sistema Financiero, mediante el cual se propone regular el sandbox. Dicha iniciativa legislativa cuenta con el apoyo de la Asociación Española de Fintech e Insurtech (AEFI), la cual afirma que "cuanto más se compaginen la seguridad jurídica y las posibilidades de innovación, evitando la sobrerregulación, más demanda habrá y, cuanta mayor demanda, mayor inversión se generará” (Invertia, 2018, párr. 7)

En la Exposición de Motivos del mencionado anteproyecto encontramos, en primer lugar, que el Regulatory Sandbox, es excluido de actividades y servicios de carácter profesional habitual, esto es, está diseñado para otorgar un espacio de pruebas controlado, seguro para sus participantes y sin riesgo en el sistema financiero. Esto lo consiguen básicamente con las "Claves de bóveda" que son las siguientes:

- Un espacio controlado; los proyectos a ejecutar no se encontrarán sujetos a legislación específica, debiéndose aplicar todo lo dispuesto en la ley y en los protocolos (anteproyecto de Ley de Medidas para la Transformación Digital del Sistema Financiero. 2018, p. 2). 
- Garantía en los objetivos de política pública; que los engloba en 3 ámbitos, "la protección de datos de carácter personal, la protección a los usuarios de servicios financieros y la prevención del blanqueo de capitales y la financiación del terrorismo" (Anteproyecto de Ley de Medidas para la Transformación Digital del Sistema Financiero. 2018, p. 2).

- Instrumento supervisor; mediante este esquema, se conocerá mejor la iniciativa aplicada a los usuarios, mediante un control de cumplimiento de la legislación vigente.

- Ley-Protocolo; mediante este concepto se busca tener una seguridad jurídica para el desenvolvimiento del Sandbox y el Protocolo contendrá un marco detallado de las obligaciones y derechos de las partes, el funcionamiento de la prueba, el periodo de tiempo entre otras cosas.

Así también, cabe mencionar que el anteproyecto cubre el funcionamiento del Sandbox Regulatorio mediante tres regímenes:

- Régimen de acceso; que viene a ser el antes del funcionamiento del proyecto, esto es, los pasos y requisitos que se deben cumplir para participar en el espacio controlado de pruebas.

- $\quad$ Régimen de garantías y protección a la clientela durante el periodo de pruebas.

- $\quad$ Régimen de salida; (anteproyecto de Ley de Medidas para la Transformación Digital del Sistema Financiero. 2018, p. 3-4)

\subsubsection{Regtech:}

Nace con el objetivo de aliviar la carga regulatoria que tiene cada país. De acuerdo con Vodanovic Legal (2018) es considerada como:

Un instrumento que soporta la función de Compliance, ayudando a las empresas a automatizar su labor de cumplimiento y a gestionar adecuadamente sus riesgos, optimizando a su vez el cumplimiento de sus obligaciones de reporte ante las distintas autoridades pertinente (p 64.)

Se creó fundamentalmente para reducir riesgos y costos relacionados con los requisitos normativos. Para BBVA Reserch (2016)

Las empresas Regtech se centran en la automatización de los procesos manuales y en los vínculos entre los pasos de los procesos de análisis/elaboración de 
informes, la mejora de la calidad de datos, la creación de una vista integral de los datos, el análisis automatizado de datos mediante aplicaciones capaces de aprender durante el proceso y la generación de informes significativos que puedan enviarse a los reguladores y utilizarse internamente para mejorar la toma de decisiones (pp. 4 -5).

Según señala Vodanovic Legal (2018), las Fintech presentan seis (06) tipos de riesgos más resaltantes, entre los cuales consideramos tres de suma importancia:

1. Seguridad de los datos personales

2. Arbitraje Regulatorio

3. Lavado de activos y financiamiento del terrorismo

Es así que el RegTech tiene como finalidad, para las empresas, controlar los riesgos y costos que implica cumplir con las obligaciones regulatorias. 


\section{CONCLUSIONES}

Consideramos al crowdfunding como el medio por el cual se da una convergencia de diversas necesidades: por un lado, podemos encontrar a grupo de emprendedores que buscan obtener financiamiento que el sistema tradicional no atiende para llevar a cabo sus proyectos; por otro lado, se encuentran las empresas que se dedican a la administración de las plataformas de financiamiento participativo y finalmente, a aquellas personas o entidades que buscan invertir sus recursos con diversos proyectos.

En la actualidad existe el proyecto de Ley N. ${ }^{\circ}$ 4324/2018-PE que aborda el crowdfunding; sin embargo, no abarca todas sus modalidades. En ese sentido, estamos de acuerdo que el equity based crowdfunding o crowdinvesting y el lending o debt based crowdfunding, sean regulados y supervisadas por la SMV, por su carácter de intermediación, como lo indica el referido proyecto.

Existen diversas investigaciones que indican que el crowdfunding está manifestando un crecimiento paulatino en el ámbito financiero; es el caso de nuestro país, donde el crowdfunding ocupa el $9 \%$ de la industria fintech, por lo que este crecimiento deberá ir acompañado de una regulación adecuada. Mediante la autorregulación regulada, el Estado permite que el sector privado delinee ciertos límites a su actividad, luego recoge esta autorregulación y la transforma en una norma que permite una regulación no disruptiva de la actividad de la empresa. Es el caso de México, donde algunas de las empresas que administran plataformas de crowdfunding, antes de la promulgación de su Ley Fintech, se asociaron y decidieron autorregularse mediante el establecimiento de un código de conducta general. Al no haberse considerado las otras dos modalidades de crowdfunding (donación y recompensa) dentro del marco del Proyecto de Ley N. ${ }^{\circ} 4324-$ 2018-PE, sugerimos el uso de la autorregulación regulada tal como ocurre en otros países.

El Buen Gobierno Corporativo es una herramienta para la autorregulación porque pone a disposición de las empresas estándares mínimos para su autocontrol. Las empresas que administran las plataformas de financiamiento participativo podrán valerse de esta estructura para la creación de Códigos de Conducta basados en principios básicos que 
regule sus funciones y permita la creación de Manuales de Procedimientos que guíe su ejecución.

\section{RECOMENDACIONES}

Es importante que nuestro país desarrolle un marco legislativo idóneo y no restrictivo para las empresas que administren plataformas de crowdfunding. De esta manera, el Estado promueve la inclusión financiera y la seguridad jurídica.

Recomendamos que todas las empresas que administran plataformas de crowdfunding en todas sus modalidades se rijan por un Código de Conducta para las Plataforma de Financiamiento Participativo que podrían tener como referencia los Principios Generales propuestos en esta investigación, los cuales fueron compilados de legislación y documentos internacionales.

En el marco de un Código de Conducta, permitirán a las empresas desarrollar procedimientos éticos a través de la creación y ejecución de manuales de procedimientos. Recomendamos que el proyecto de Ley N. ${ }^{\circ}$ 4324-2018-PE que regula el régimen jurídico de las plataformas de financiamiento participativo financiero no sea modificado, pues al igual que lo señalado por la Ley de Fomento de la Financiación Empresarial de España, disponga la obligatoriedad de las sociedades administradoras de plataformas de contar con un reglamento interno de conducta para solicitar su autorización e inscripción ante el ente regulador.

Debemos considerar las propuestas internacionales tales como el Sandbox Regulatorio y Regtech como alternativas de control de riesgos. El primero, funcionaría como plataforma experimental dirigida por el Estado, donde todos los actores (empresas, emprendedores e inversionistas) cuenten con seguridad jurídica y se genere competitividad. El segundo, considerado una herramienta tecnológica, que serviría como política de cumplimiento para que las empresas puedan reducir los costos de implementación, disminuyendo los riesgos según las características de cada empresa. 


\section{REFERENCIAS}

ABC España. (2016). El fraude del «crowdfunding». Recuperado de https://www.abc.es/tecnologia/informatica/soluciones/abci-fraudecrowdfunding-201510291227_noticia.html

Acuerdo Nacional - Perú. (2002). Políticas. Recuperado de: https://acuerdonacional.pe/politicas-de-estado-del-acuerdo-nacional/politicasde-estado\%E2\%80\%8B/politicas-de-estado-castellano/iii-competitividad-delpais/18-busqueda-de-la-competitividad-productividad-y-formalizacion-de-laactividad-economica/

Agencia Estatal Boletín Oficial del Estado - Gobierno de España. (2018). Ley 5/2015, de 27 de abril, de fomento de la financiación empresarial. Recuperado de: https://www.boe.es/buscar/act.php?id=BOE-A-2015-4607

Alemany, L y Bultó, I. (2014). Crowdfunding: Nueva forma de financiación para los emprendedores. Revista: Harvard Deusto: Business Review Número N. 237 (Septiembre 2014). Recuperado de: http://itemsweb.esade.es/wi/research/eei/Articles/HDBR237_06-

19_Crowdfunding nueva_forma_de financiacion_L\%20A\%20_y_I\%20B\%20.pd $\underline{\mathrm{f}}$

Alianza del Pacífico. (2018). ¿Qué es la Alianza del Pacífico?. Recuperado de: https://alianzapacifico.net/que-es-la-alianza/

Alianza del Pacífico. (2018). XVII Reunión de Ministros de Finanzas de la Alianza del Pacífico. Recuperado de: https://alianzapacifico.net/xvii-reunion-de-ministrosde-finanzas-de-la-alianza-del-pacifico/

Arborius. (2018). Conectando empresas $e$ inversores. Recuperado de: https://www.arboribus.com/sobre-arboribus/quienes-somos-empresas.html 
Arboribus. (2014). Entrevista a Jonatan Buxeda, socio de Oxbridge, empresa financiada por Arboribus. Recuperado de: https://blog.arboribus.com/entrevista-a-jonatanbuxeda-socio-de-oxbridge-empresa-financiada-por-arboribus/

Asociación Española de Fintech e Insurtech. (2018). Código de Buenas Prácticas para las Fintech y las Insurtech. Recuperado de: https://asociacionfintech.es/wpcontent/uploads/2018/05/Codigo_Buenas_Pr\%C3\%A1cticas_2018.pdf

Asociación de Plataformas de Fondeo de México - AFICO. (2016). Código de Conducta. Recuperado de: http://www.afico.org/uploads/9/3/1/2/93128428/co\%CC\%81digo_de_e\%CC\%8 $\underline{1 \text { tica.pdf }}$

Asociación de Bancos del Perú - ASBANC. (2017). Una mirada al fenómeno fintech en el Perú y el mundo. Recuperado de: https://www.asbanc.com.pe/Publicaciones/ASBANC-Semanal-242.pdf

Banco Continental. (2015). Case Study: Hemav, the crowdfunding success of drones. Recuperado de: https://www.bbva.com/en/case-study-hemav-crowdfundingsuccess-drones/

Banco Continental - BBVA - Innovation Center. (2015). Conoce todos los detalles del ecosistema financiero alternativo. Finanzas P2P. Recuperado de: https://es.slideshare.net/cibbva/ebook-finanzas-p2p-un-ecosistema-alternativo

Banco Continental - BBVA - Innovation Center. (2015). La alternativa financiera para inversores $y$ emprendedores crowdfunding. Recuperado de: https://www.bbva.com/wp-content/uploads/2017/10/ebook-crowdfunding-unaalternativa-financiera-para-emprendedores-e-inversores_2.pdf

Banco Continental - BBVA. (2017). Así es la primera promoción del primer 'sandbox' para 'fintech'. Recuperado de: https://www.bbva.com/es/asi-la-primerapromocion-del-primer-sandbox-fintech/

Banco Continental - BBVA. (2018). El 'sandbox' es una apuesta decidida por la transformación digital del sector financiero. Recuperado de: 
https://www.bbva.com/es/sandbox-apuesta-decidida-transformacion-digitalsector-financiero/

Banco Continental - BBVA Research. (2016). Situación Economía Digital. Recuperado de:

https://www.bbvaresearch.com/wpcontent/uploads/2016/02/Situacion_ED_feb16.pdf

BID, BID|Invest, Finnovista. (2018). FINTECH - América Latina 2018 Crecimiento y consolidación. Recuperado de: https://publications.iadb.org/en/fintech-latinamerica-2018-growth-and-consolidation

Bolsa de Comercio de Rosario. (2018). Crowdfunding en Argentina: claves de la reglamentación. Recuperado de: https://www.bcr.com.ar/Pages/Publicaciones/informativosemanal_noticias.aspx?p $\underline{\text { IDNoticia }=995}$

Bregante, D. (2017). Regulación 2.0: El Reto de la Regulación Fintech en el sistema financiero peruano. Recuperado de: https://www.up.edu.pe/UP_Landing/alacde2017/shortspapers/14-Regulacionreto-regulacion-sistema-financiero-peruano.pdf

Burkett, E. (2011). A crowdfunding exemption? Online investment crowdfunding and U.S. securities regulation. Recuperado de: http://trace.tennessee.edu/cgi/viewcontent.cgi?article=1235\&context=transactions $\underline{\text { sei-redir }=1 \& \text { re }}$

Cámara de Diputados - Congreso de la Unión - México. (2018). Ley para Regular las Instituciones de Tecnología Financiera. Recuperado de: http://www.diputados.gob.mx/LeyesBiblio/pdf/LRITF_090318.pdf

Castells, M. (2012). Reseña: Redes de indignación y esperanza: los movimientos sociales en la era de Internet. Recuperado de: https://dialnet.unirioja.es/descarga/articulo/5106084.pdf

Civislend PFP, S.A. (2017). Reglamento Interno de Conducta de Civislend PFP S.A. Recuperado de: https://www.civislend.com/politica-de-privacidad 
Conde, J. (2007). ¿Existe una forma óptica de gobierno corporativo? Problemas, Principios y Modelos de Propiedad y Control. Revista Peruana de Derecho de la Empresa. 39-73.

Congreso de la República del Perú. Proyecto de Ley N. ${ }^{\circ}$ 3403-2018-CR Ley que declara de interés nacional y necesidad pública la regulación de la tecnología financiera - Fintech. Recuperado de: http://www.congreso.gob.pe/pley-2016-2021

Congreso de la República del Perú. Proyecto de Ley N. ³083/2017-CR Proyecto de Ley mediante el cual propone la Ley que regula el régimen jurídico de las Plataformas de Financiamiento Participativo - PFP. Recuperado de: http://www.congreso.gob.pe/pley-2016-2021

Congreso de la República del Perú. Proyecto de Ley 03083/2017-CR - Ley que regula el régimen jurídico de las plataformas de financiamiento participativo-PFP. Recuperado de: http://www.congreso.gob.pe/pley-2016-2021

Congreso de la República del Perú. Proyecto de Ley 03403/2018-CR - Ley que declara de interés nacional y necesidad pública la regulación de la tecnología financiera (Fintech). Recuperado de: http://www.congreso.gob.pe/pley-2016-2021

Congreso de la República del Perú. Proyecto de Ley 04324/2018-PE - Ley que regula el financiamiento participativo financiero. Recuperado de: http://www.congreso.gob.pe/pley-2016-2021

Congreso de la República del Perú. Proyecto de Ley 04421/2018-CR - Ley que norma el desarrollo de la tecnología financiera en el Perú - Fintech. Recuperado de: http://www.congreso.gob.pe/pley-2016-2021

Coronado, C. y Larrañaga, J. (2015). La financiación por medio del crowdfunding del audiovisual: el caso del cortometraje Juan y la nube. http://dx.doi.org/10.5209/rev_DCIN.2015.V38.50816

Deloitte Legal. (2018). Decreto por el que se expide la Ley para Regular las Instituciones de Tecnología Financiera (Ley Fintech). Recuperado de: https://www2.deloitte.com/mx/es/pages/legal/articles/decreto-ley-fintech.html 
Diario Gestión. (18 de mayo de 2015). BBVA Research: Regulando el crowdfunding financiero. Recuperado de: https://gestion.pe/opinion/bbva-research-regulandocrowdfunding-financiero-90156

Diario Gestión. (09 de mayo de 2018). BCR: El crowdfunding necesita regulación que proteja al cliente y a las fintech. Recuperado de: https://gestion.pe/economia/bcrcrowdfunding-necesita-regulacion-proteja-cliente-fintech-233247

Diario Gestión. (09 de enero de 2014). El crowdfunding a través de la emisión de valores o aportes de capital no están autorizados, advierte la SMV. Recuperado de: https://gestion.pe/economia/mercados/crowdfunding-traves-emision-valoresaportes-capital-autorizados-advierte-smv-1705?ref=gesr

Diccionario Jurídico Espasa. Seguridad Jurídica. Edición 2001. Madrid. Editorial Espasa Calpe S.A.

EAE Business School. (2015). ¿De dónde nace el crowdfunding y qué beneficios supone?. Recuperado de: https://retos-directivos.eae.es/de-donde-nace-elcrowdfunding-y-que-beneficios-supone/

Estudio Echecopar. (25 de agosto de 2017). Seis ideas para reformar el mercado de capitales peruanos. Diario Gestión. Recuperado de: https://gestion.pe/blog/agenda-legal/2017/08/seis-ideas-para-reformar-elmercado-de-capitales-peruanos.html?ref=gesr

Finnovista. (2017). Fintech Radar Perú: 47 Startups Fintech impulsan la oferta de mejores servicios financieros en Perú. Recuperado de: https://www.finnovista.com/fintech-radar-peru-45-startups/

Fintech México. ¿Qué es Fintech? Recuperado de: https://www.fintechmexico.org/qu-es-fintech/

Franco, P. (2017). Tecnología, inclusión financiera y regulación: acercando el financiamiento a las personas. Recuperado de: http://www.up.edu.pe/UP_Landing/alacde2017/papers/25-Tecnologia-inclusionfinanciera-regulacion.pdf 
Gallego, A. (2011). Crowdfunding: implementation decisions in creative industries in emerging countries. Revista Kepes. (Año 8 N. ${ }^{\circ}$ 7). 160-169.

García, D. y Alonso, A. (2014). Financiación Empresarial 2.0: Crowdfunding para inversión y otras plataformas. Recuperado de: https://www.fef.es/.../papelesde.../957_e61d6da840b7707cb1f0b9107669b78d.html

García de la Cruz, R. (2017). Presentación oficial de la alianza fintech Iberoamérica. Recuperado de: http://www.finnovating.com/news/presentacion-oficial-la$\underline{\text { alianza-fintech-iberoamerica/ }}$

Gil, E. (2015). Nuevos activismos sociales en la era digital: de las masas al crowd. http://dx.doi.org/10.5209/POSO.48914

Hundskopf. O. (2004). Compatibilización entre las prácticas de buen gobierno corporativo y la ley general de sociedades. Revista Actualidad Jurídica N. ${ }^{\circ} 126$ (mayo). $43-62$.

Invertia. (2018). Las empresas fintech aplauden la creación de un sandbox. Recuperado de: https://www.invertia.com/es/noticias/actualidad/20180711/las-empresasfintech-aplauden-la-creacion-de-un-sandbox-35769

Lasén, A. (2009). Las nuevas formas de acción colectiva desafían la lógica de la representación. Recuperado de: http://www.enmedio.info/las-nuevas-formas-deaccion-colectiva-desafian-la-logica-de-la-representacion/

La Tribu Colaboradora. (2015). Pebble: validación y crecimiento con crowdfunding. Recuperado de: http://latribucolaborativa.com/pebble-validacion-crecimientocrowdfunding/

La voz de los Emprendedores. (2018). Plataformas de Crowdfunding en Perú. Recuperado de: https://www.pqs.pe/emprendimiento/plataformas-crowdfundingperu-prodem

Le Bon, G. (1895). Psicología de las Masas. Recuperado de: https://seryactuar.files.wordpress.com/2012/12/psicologc3ada-de-las-masasgustave-le-bon-1895-pdf.pdf 
López, C. (2012). Los principios del buen gobierno corporativo y la ley general de sociedades. Revista Jurídica del Perú - N. ${ }^{\circ} 134$ (abril). 315-323.

Marcilla, G. (2005). Desregulación, Estado Social y Proceso de Globalización. Recuperado de: http://www.cervantesvirtual.com/obra/desregulacin-estado$\underline{\text { social-y-proceso-de-globalizacin-0/ }}$

Martínez, J. (2007). Los orígenes del movimiento por el buen gobierno corporativo. Revista Peruana de Derecho de la Empresa - N. ${ }^{\circ} 64$ (noviembre). 19 - 38.

Ministerio de Economía y Empresa de España. (2018). Anteproyecto de Ley de medidas para la transformación digital del Sistema Financiero. Recuperado de: http://www.mineco.gob.es/stfls/mineco/prensa/noticias/2014/180711_AP_Ley_t ransformacion_digital_sistema_financiero_f.pdf

Ministerio de Hacienda de Chile. (2018). Principios orientadores para la regulación Fintech en la Alianza del Pacífico. Recuperado de: http://www.hacienda.cl/mercado-de-capitales/documentos-ypresentaciones/principios-orientadores-para-la.html

Ministerio de Economía y Finanzas. (2018). XVI Reunión de Ministros de Finanzas de la Alianza del Pacífico. Recuperado de: https://www.mef.gob.pe/es/noticias/notas-de-prensa-y-comunicados?id=5669

Ministerio de Justicia y Derechos Humanos - Argentina. (2018). Ley 27349 - Apoyo al Capital Emprendedor. Recuperado de: http://servicios.infoleg.gob.ar/infolegInternet/anexos/270000274999/273567/norma.htm

Ministerio de Justicia y Derechos Humanos - Argentina. (2018). Resolución General 717-E/2017. Recuperado de: http://servicios.infoleg.gob.ar/infolegInternet/anexos/305000309999/305469/norma.htm

Nuevo Financiero. (2017). Crowdfunding de donaciones, micromecenazgo para proyectos solidarios $y$ de interés común. Recuperado de: 
https://nuevofinanciero.com/crowdfunding-donaciones-solidarios-interescomun/

Padilla, A. (2017). ¿ Quién regula a las empresas de crowdfunding?. Recuperado de: https://www.entrepreneur.com/article/296702

Revista+Finanz@s. (2018). Balance del primer año de la Alianza Fintech Iberoamérica. Recuperado de: http://masfinanzas.com.pe/fintech/balance-del-primer-ano-de-la$\underline{\text { alianza-fintech-iberoamerica/ }}$

Rheingold, H. (2004). Multitudes inteligentes. La próxima revolución social. Recuperado de: https://es.scribd.com/document/34839538/Multitudes-Inteligentes

Rodríguez, T. (2013). El crowdfunding: una forma de financiación colectiva, colaborativa y participativa de proyectos. Recuperado de: http://www.derecho.uba.ar/publicaciones/pensar-en-derecho/revistas/3/elcrowdfunding-una-forma-de-financiacion-colectiva-colaborativa-y-participativade-proyectos.pdf

Rodríguez, T. (2006). El régimen jurídico de los mercados electrónicos cerrados (eMarketplaces). Recuperado de: https://www.marcialpons.es/media/pdf/100768769.pdf

Rodríguez, T. (2013). Modelos Jurídicos para el Crowdfunding: nuevas formas de financiación colectiva de proyectos. Revista jurídica argentina La Ley. 10091019.

Sagol, C. (2017). Multitudes inteligentes (o la unión de las mentes hace a la fuerza. Recuperado de: http://campus.unla.edu.ar/6102017-multitudes-inteligentes-o-launion-de-las-mentes-hace-a-la-fuerza/

Santy, L. (2017). El interés público en el derecho administrativo peruano y en el derecho administrativo francés. Recuperado de: http://www.escuelasat.edu.pe/website/Portals/1/files/revistas/Actualidad\%20Gu bernamental/Dic\%2017/EL_INTERES.pdf 
Silvia, M. (2017). El acelerado crecimiento de las fintech y los desafíos para su regulación. Revista Moneda 171: Serie Numismática Fauna Silvestre amenazada del Perú. Recuperado de: http://www.bcrp.gob.pe/docs/Publicaciones/RevistaMoneda/moneda-171/moneda-171-08.pdf

Sociedad de la Innovación. (2015). "4 tipos de crowdfunding. ¿Los conoces todos?” Recuperado de: https://www.sociedaddelainnovacion.es/4-tipos-decrowdfunding-los-conoces-todos/

Superintendencia de Banca, Seguros y AFP - SBS. (2019). Portal de Inclusión Financiera. Recuperado de: http://www.sbs.gob.pe/inclusionfinanciera/Estrategia-Nacional

Superintendencia de Banca, Seguros y AFP - SBS. (2015). Estrategia Nacional de Inclusión Financiera. Recuperado de: http://www.sbs.gob.pe/Portals/0/jer/inclusion_financiera/ESTRATEGIANACIONAL-INCLUSION-FINANCIERA.pdf

Superintendencia de Banca, Seguros y AFP - SBS. (2017). Memoria Anual 2017. Recuperado de: http://www.sbs.gob.pe/Portals/0/jer/PUB_MEMORIAS/Memoria_2017_new_2 018.pdf

Superintendencia de Mercado de Valores - SMV. (2002). Código de buen gobierno corporativo para las sociedades peruanas. Recuperado de: http://www.smv.gob.pe/Uploads/CodBGC2013\%20_2_.pdf

Superintendencia de Mercado de Valores - SMV. (2018). Comunicado el crowdfunding mediante la emisión de valores o aportes de capital a través de plataformas de internet no está autorizado. Recuperado de: https://www.smv.gob.pe/Uploads/AvisoCrowfunding.pdf

Superintendencia de Mercado de Valores - SMV. (2017). Proyecto Ley de Tecnología Financiera. Recuperado de: https://www.smv.gob.pe/Uploads/1Ley_FinTech_Mexico.pdf 
Teaming. (2018). ¿Qué es teaming? Recuperado de: https://www.teaming.net/que-esteaming

Vodanovic Legal. (2018). El Panorama de la Industria Fintech en el Perú. Recuperado de: $\quad$ https://vodanovic.pe/wp-content/uploads/2018/11/Estudio_2018Vodanovic_Legal.pdf

Yun, H. (01 de enero de2014). El crowdfunding: Una útil herramienta para financiar emprendimientos. El Comercio. Recuperado de: https://elcomercio.pe/economia/negocios/crowdfunding-util-herramientafinanciar-emprendimientos-282804

Zunzunegui, F. (2014). Shadow Banking, Crowdfunding y seguridad jurídica. Recuperado de: http://www.rdmf.es/wp-content/uploads/2014/01/zunzuneguishadow-banking-crowdfunding-y-seguridad-jurdica.pdf 